\title{
Designing and disseminating diy assistive technology in an online environment:
}

How can digitally connected communities have a positive influence on the psychosocial impact of stroke?

by Tom Creagh

A 90-point thesis submitted to Victoria University of Wellington in partial fulfillment of the requirements for the degree of Master of Design Innovation in Media Design

Victoria University of Wellington, 2017

School of Design 
The URL for the web application:

http://thesis-tom.herokuapp.com/

(Please note this web application has been designed for handheld devices. Specifically the iPad)

The code repository for the web application can be found at: https://github.com/ehinger/thesis 


\section{Acknowledgements}

I would like to thank my supervisor Kah Chan first and foremost for providing me with his guidance and expertise.

I would like to thank Dr Edgar Rodriguez Ramirez for his guidance also.

Thankyou to my family and friends for all their support during my studies.

Lastly, thank you to my fellow graduate students for all their help and support. 


\section{Abstract}

Stroke is a debilitating neurological condition caused by a dysfunction in the flow of blood to the brain (Stroke.org, 2016). The onset of stroke can result in complex disability that may require long term rehabilitation (Duncan, 1994). The deterioration of psychosocial well-being is one of the many issues that may result from the formation of disability in an individual (Aström, 1992). Dunn (2000) defines psychosocial as "how people think and feel about, influence, and relate to actual, imagined, or assumed others". It is about how our concept of self influences our relationships with others and vice versa.

The purpose of this research is to investigate what influence digitally connected communities can have on psychosocial recovery from stroke. This will be achieved through the creation of a web application. This web application will expand on the idea of diy and non-intentional design (Brandes, 2008) and apply it in a rehabilitative manner. Non-intentional design is defined by Brandes (2008, p) as, "the everyday, unprofessional redesign of professionally designed objects. NID results when an object is used in a manner different from the prescribed (and therefore restricted) functional intention or when the prescribed application is not honored in the new uses". The intention being that influencing assistive technology use in a positive way can help a person accept disability into their concept of self and help that person to regain confidence to engage with others socially.

This research initially canvasses literature reviews (Hanington et al, 2012) to analyze the psychosocial, elderly engagement with web applications, and to develop heuristics to guide the design of the web application. Subsequently, I have used precedent reviews (Hanington et al, 2012) to analyze diy assistive technology documentation in an online environment. Finally, I utilised a Research through design (Frayling, 1993) approach to inform the creation of this diy assistive technology and the web application. User testing of the web application was then performed. The testing took the participants through the process of using the web application via a set list of tasks and also asked them to recreate one of the three available diy assistive technology examples. 


\section{Table of contents}

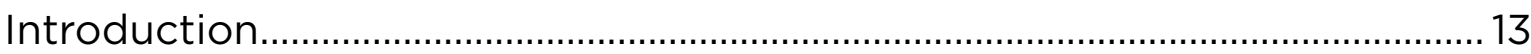

Abstract

Research overview

Chapter 1 - Methodology

Methods

Aims and objectives

Chapter 2 - Literature Review

Stroke

Psychosocial

Assistive technology

Diy

Summary

Chapter 3 - Precedent Analysis

Documentation review

Precedents

Precedent Analysis

Chapter 4 - Persona development

Experience vs expertise

Cognitive difficulties

Perceptual difficulties

Motor deficiencies

User behaviour

Personas 
Chapter 5 - Heuristics.

Technical analysis

Device selection

New Zealand web accessibility standards

Heuristics

The concept

Chapter 6 - Technical Development

First steps

Normalising the database

Security

Imagery

Front end

Chapter 7 - Design process 65

Minimum viable product

Home page

Diy creation page

Documentation page

Expansion

Changes

Profile page

Ability profile

Settings page

Personal diy page

Heuristics review

Finalised user interface

Aesthetics 
Chapter 8 - DIY assistive technology 101

Pick up tool

Typing tool

Utensil holder

Chapter 9 - User testing 109

Participants

Testing procedure

Testing results

Interviews

Participant A

Participant B

User testing sessions and questionnaires

Participant A test

Observations

Questionnaire

Participant B test

Observations

Questionnaire

Chapter 10 - Conclusion

Limitations

Summary

Discussion

Reference list

List of figures 
Introduction 


\section{Research overview}

The following details the contents of each chapter within this thesis:

Chapter 1: Establishes the methods and aims and objectives used to form this thesis.

Chapter 2: Through use of a qualitative literature review, background information is introduced and expanded upon. Stroke is introduced first and key demographics are identified, next the psychosocial is introduced and a problem surrounding including disability into the formation of self and how that affects assistive technology adoption and/or abandonment is framed, assistive technology is then expanded upon, and finally diy is introduced as a potential counter to many of the outlined issues.

Chapter 3: A review of literature pertaining to diy documentation in an online environment was performed to identify criteria to inform a precedent analysis on relevant precedents. This was undertaken to help inform the creation of a set of heuristics and to establish potential functionality within the web application.

Chapter 4: The demographics identified from the qualitative literature review were then expanded upon to create a set of personas. These personas were used to help inform the development of a set of heuristics.

Chapter 5: An analysis of technical requirements was performed to establish an appropriate device to design the web application for and to inform the development of a set of heuristics. A set of heuristics created to inform the design of the user interface of the web application are elaborated. The web application is introduced including features and intended use.

Chapter 6: The initial development process is then discussed. This focuses on the technical development of the web application: the requisitioning of a database, the normalising of the database tables, security considerations, and front end considerations.

Chapter 7: The development of the user interface is then discussed. Each stage of the design process is elaborated on and how the heuristics informed 
various design decisions is explained.

Chapter 8: The development of three diy assistive creations is elaborated on for the purpose of populating the web application in preparation for user testing.

Chapter 9: The user testing that was performed is then elaborated on. This includes participant recruitment, testing protocol, and testing results.

Chapter 10: The concluding thoughts are established regarding theories introduced within this thesis. 


\section{Methodology}

\section{How can digitally connected communities have a positive influence on the psychosocial impact of stroke?}

During the first phase of this research qualitative literature reviews (Hanington, Martin, 2012) were performed. These reviews were used a means of framing the problem this thesis has addressed through the analysis of relevant literature. The literature review initially provides a background to stroke then frames relevant problems regarding psychosocial impact of stroke and corresponding issues associated with assistive technology, finally, it theorised that diy may be a possible solution to the outlined problems.

During the second phase an approach of research through design was implemented. Research through design is based off of Christopher Frayling's (1993) research into design practice in which he initially identified three types of design research: research into design, research through design, and research as design. Each of the three types are equally valid, however, research through design was chosen because it allows the final design output to be used to communicate the results. This method implemented sketching and iterative design to make up most of the design phase.

\section{The methods applied:}

\section{Personas:}

Personas are fictional user profiles that are created to help understand common behaviors of a chosen demographic (Hanington, Martin, 2012). Personas were created for this research based upon the literature reviews. Relevant literature was used to determine a target demographic and general user behaviour.

Heuristics evaluation:

A heuristics evaluation is a usability analysis based on a predetermined set of guidelines (Hanington, Martin, 2012). Using knowledge gained from the literature reviews, an analysis of design precedents, and personas, a set of heuristics was developed to influence the design of the initial user interface. Afterwards, the finalised user interface was assessed based on the heuristics 
to correct usability errors before testing took place.

Interview:

An interview (Hanington, Martin, 2012) was used before user testing took place. The questions covered the participants general information, history with stroke, past and current use of assistive technology, and past and current use of the internet. These topics were covered to assess and gain some insight into information gathered from the literature reviews.

Usability testing:

Usability testing is used to assess the usability of user interfaces by members of the appropriate demographic. The participant is given a set of tasks that reflect typical end-user goals that they must perform to the best of their ability. For this research the users were given 5 tasks. The first four were based on interaction with features within the web application and the final task required the participant to create a small, physical object based on instructions within the web application. The participants were assessed based on completion time, how many of the tasks they could complete, and accuracy of results.

Questionnaire:

A questionnaire was used directly after the user testing to determine usability. The questionnaire was based on the quantitative SUS (system usability scale) (Sauro, 2011) which is a set of ten usability questions that uses the level of agreement version of the likert scale (Vagias, 2006) (a 5 point scale that begins with strongly disagree and transitions to strongly agree) to determine an answer to each question. The questionaires were then tallied up based on the score for each answer. This score was in the range of $0-4$ resulting in a number between 0 - 40. This final number was then multiplied by 2.5 to receive a result between $0-100$.

\section{Aims and objectives}

Identify key issues associated with assistive technology within the context of the psychosocial for stroke patients with stroke induced physical disabilities:

- Investigate assistive technology difficulties within the context of the psychosocial.

- Investigate current assistive technology themed web applications and 
identified user base.

- Establish design criteria for web application based on investigation.

Design, develop, and test appropriate web application for stroke patients with stroke induced physical disabilities:

- Design and develop functional web application harnessing appropriate technology.

- Establish contact with appropriate and willing stakeholders.

- Test quality of finalised web application with willing and appropriate stakeholders. 


\section{Literature review}




\section{Background}

The following Literature review is divided into four topics: Stroke, psychosocial, assistive technology, and diy. It begins by providing an overview of stroke: What it is, it's consequences, and who it affects. It then moves into the psychosocial discussing what it is and framing a problem based around disabled identity and the use of assistive technology. Afterwards, It provides greater detail on assistive technology and outlines issues based around the procurement and abandonment of assistive devices. Lastly, it introduces and presents diy as a potential means of countering the issues associated with identity and assistive technology procurement and abandonment, and then provides some detail on maker communities within an online environment.

The four topics outlined by this literature review provide the rationale for this research in having a positive impact on psychosocial recovery post-stroke through online means.

\section{Stroke}

Stroke is a neurological condition caused by a dysfunction in the flow of blood to the brain. It is subdivided into two types: ischaemic (caused by blood clot) and haemorrhagic (caused by bleeding) (Stroke.org, 2016). In 2014, stroke was the "third most common cause of long-lasting disability" (Brauer et al, 2014, p. 1) internationally. Stroke induced disability, however, is complex due to the variation in severity between survivors but also in the variety of potential disabilities that can occur (Duncan, 1994). While these disabilities can affect both the cognitive and physical functioning of survivors, this research will focus solely on the physical consequences of stroke. Common physical disabilities caused by stroke can include but are not limited to hemiparesis/ hemiplegia (paralysis of the upper or lower limbs or both on the right or left side of the body), spasticity (contraction or spasming of the muscles in the lower or upper limbs), paralysis (loss of feeling and movement in the body), foot drop (inability to lift the front part of the foot), and fatigue (lowered energy levels)(Stroke.org, 2016). Stroke was chosen as the focus of this research due to this variation in disability caused.

The onset of stroke is sudden and can affect a person at any age however the chances of stroke occurring increase as a person gets older. In New Zealand 
during 2006/2007 0.8 percent of the male population and 1.1 percent of the female population aged 45-54 experienced a stroke, that increased to 3.3 percent for males and 1.9 percent for females between the ages of 55-64, it increased again to 5 percent equally between males females between the ages of 65-74, and then grew dramatically to 12.8 percent for males and 10 percent for females ages 75 plus (Ministry of Health, 2008). While primarily weighed towards people aged 65+, these statistics indicate that a significant portion of the New Zealand population was affected by stroke. One in nine of those affected by stroke were actively engaged in some form of rehabilitation while one in three required it but were not engaged at all (Ministry of Health, 2008), this coupled with stroke being the third biggest cause of longterm disability internationally during 2014 (Brauer et al, 2014) indicates the volume in which disablement occurs post stroke.

\section{Psychosocial}

One major concern especially amongst adults with a newly acquired disability/s like that gained from stroke is stigma associated with assistive technology (Hocking, 1999). Stigma is a social phenomena where there is a "mark (attribute) that links a person to undesirable characteristics (stereotypes)" (Link, Phelan, 2001). Stigma impacts a person's formation of self identity by having an impact on social interaction. Self identity is based in part on social feedback and how a disabled person incorporates disability into their self identity can greatly impact assistive device use (Pape et al, 2002). The issue of stigma in regards to assistive technology, however, is part of a greater issue surrounding disability: psychosocial response to disability.

Psychosocial can be described as "how people think and feel about, influence, and relate to actual, imagined, or assumed others" (Dunn, 2000, p1). It is about how our concept of self influences our relationships with others and vice versa. A person's concept of self is generated by a number of factors: A person's past, present and future, culture, the social environment, the physical environment, and physical characteristics (both physical appearance and ability) (Dunn, 2000)(Hocking, 1999)(Hocking, 2008)(Pape et al, 2002). The following analysis of the psychosocial will be in relation to assistive technology use.

Who a person has been in the past, who they are in the present and the person they wish to be are all building blocks of a person's concept of self 
(Hocking, 1999). Both past and present actions and beliefs held by a person as well as future goals and aspirations can be largely driven by the culture and the social environment they inhabit. These two influences create a roadmap of what can be considered a 'normal' path in life for a person to travel. Disability, however, greatly alters a person's ability to keep following that path which in turn alters their concept of self (Pape et al, 2002).

The willingness to accept assistive technology is reliant on disability becoming a part of a person's concept of self. It has been theorised multiple times that our possessions reflect our identity (McCracken, 1988)(Fidler, 1999). Through acquiring and discarding objects we construct an identity for ourselves (Hocking, 1999). It has been found that people tend to "actively select things that fit or enhance their self-image and to neglect or discard those that don't" (Hocking, 2008, p11). The role of object possession primarily falls into two categories: Instrumental (the object's function which allows for control over a physical environment), and symbolic (the expressiveness of an object in relation to a person's uniqueness, their qualitative values, and relationships. It also symbolises group membership, social position and status.) (Barber, 1996). Visible assistive technology reflects an identity of being disabled and all of the stereotypes that follow that categorisation become attached to the user (Hocking, 1999).

\section{Assistive technology}

Assistive technology is a classification for "objects which help people with disabilities to compensate or alleviate their impairments in daily tasks" (Barros, Cruz, Duarte, 2010, p1). These tasks can be minor activities like lifting an object off of the ground or more complicated activities like getting dressed. Assistive technology is meant to promote independence and improve self-efficacy and to some degree it does. A good amount of literature suggests that assistive technology reduces the need for personal care by the disabled (Agree, Freedman, 2004)(Hoening, Taylor, Sloan, 2003)(Verbrugge, Rennert, Madans, 1997).

Although assistive technology increases independence, abandonment rates amongst users have been found to be high. Reasons for this abandonment of assistive technology can include difficulty of use, poor instructions regarding use, ineffectiveness and being unreliable (Hocking, 1999). Initial adoption 
can be difficult also; Agree and Freedman (2004) found that a large concern regarding assistive technology was that of unmet needs. They indicate that studies done on unmet needs have, in the past, focused on personal care as a solution. Due to the reduced desire to access personal care many disabled adults currently maintain these unmet needs. Another reason unmet needs can arise is through changing needs. Hurst and Tobias (2011) found that due to cost and having to negotiate with various funding agencies, gaining possession of assistive technology can be a timely and difficult process and that needs regularly changed over that period. Indicating ease of procurement is another roadblock for a person with post stroke disability to accept assistive technology.

\section{DIY}

Diy (do it yourself), in relation to assistive technology, is a method of object creation that "refers to the creation and adaptation of assistive devices by non-professionals" (Hook et al, 2014, p1) another slightly different version of this is non-intentional design (Brandes, 2008). Non-intentional design is defined by Brandes (2008, p) as, "the everyday, unprofessional redesign of professionally designed objects. NID results when an object is used in a manner different from the prescribed (and therefore restricted) functional intention or when the prescribed application is not honored in the new uses". Both methods are sometimes used by the disabled, their families, friends and caretakers when commercially made assistive devices or the processes that provide assistive devices fail to meet their needs (Hook et al, 2014). Reasons for adoption of a diy approach reflect a failure in the instrumental role of object possession and often coincide with reasons for rejection of assistive technology: Unmet needs, inability to acquire commercially made assistive devices due to financial reasons or shortage of time, poorly designed assistive devices or poor integration with an environment (Barros, Cruz, Duarte, 2010).

Diy fulfils a symbolic role in object possession through the self expression allowed via customisation of the object during creation, and more importantly the engagement with community through the acquisition of knowledge in regards to building the assistive device (Barros, Cruz, Duarte, 2010) (Kuznetsov, Paulos, 2010). With the growing number of maker communities in recent years due to advancements in technology this engagement with community via learning often comes through use of the internet. Kuznetsov \& Paulos (2010) found that this knowledge is gained through both learning and 
teaching; both encouraging participation within a community. They found that 'through features such as discussion forums, the 'instructable' format, images and video" (Kuznetsov, Paulos, 2010, p301-302) people are able to ask and answer questions which they found to be the core process to spreading methods and ideas amongst community members. Through this inclusion in a larger community social network an individual can maintain a degree of stability, predictability, and self worth which in turn positively influences the individual's well being (Cohen, Wills, 1985).

\section{Summary}

Assistive technology use is theorised to be largely dependent on acceptance of disability into a person's concept of self especially for someone dealing with stroke induced disability. A person's concept of self in part drives their ability to form and maintain social relationships and how comfortable they are with their disability can negatively or positively affect those relationships. The rejection of assistive technology can be categorised as a failure in the in the symbolic role of object possession (the expressiveness of an object in relation to a person's uniqueness, their qualitative values, and relationships). This means that if the object being used doesn't reflect the values they hold or the person they wish to be then there is a strong chance of rejection of that object. There has been some success in the instrumental role of object possession (the object's function which allows for control over a physical environment) due to assistive technology having been shown to reduce the need for personal care resulting in higher levels of independence for the disabled. There have also been failures, however, in the instrumental role of object possession with other reasons for rejection including unmet needs and difficulty acquiring assistive technology.

Do it yourself assistive technology has been theorised as a potential solution to these issues of rejection of assistive technology. Diy counters problems in relation to the symbolic role of object possession through the customisation element and community engagement (typically in an online environment) involved in the creation process. Reasons for adoption of diy has also shown to correlate with reasons of rejection. The dissemination of diy in an online environment could result higher rates of assistive technology acceptance through object customisation. 
Precedent analysis 


\section{Documentation and distribution of online diy}

Due to the output of this thesis being a web application great consideration needed to made towards the documentation of diy creations in an online environment; both for the creator documenting their work and for the reader looking to recreate an object. A precedent analysis of similar websites was undertaken with analysis based on criteria established by relevant literature expanded on in the following section. The purpose of this precedent analysis being to identify potential useful features that could be implemented and to establish best practice to help inform the creation of a set of heuristics.

\section{Documentation analysis}

Creators, in the context of online diy, are those who design and document objects for others to recreate. The act of documenting will be one of the two core activities when engaging with this web application; the other being recreating. According to Tseng and Resnick (2014) creators engage in two modes when going through this process: Documenting and designing. They indicate that the documenting process can often be complex and requires multiple, specific tools to successfully complete which can hamper the design process. They theorise that a more seamless way to document can improve this process and allow for more accurate documentation.

Readers are those looking to recreate the diy creations they find online. For the recreation side of the process Tseng and Resnick (2014) found that readers tended to use the creator's documentation as a reference rather than as an explicit guide. They found readers often changed recommended materials and tools due to differences in availability. They recommend a "process over product" (Tseng, Resnick, 2014, p 428) style of documentation so readers can more accurately decide on techniques to use.

One more factor to consider is that of social engagement in the diy documentation process. While recreating diy creations is a mostly solo process, social interaction is still woven throughout (Bly, McDonald, Schilit, Torrey, 2007). Knowledge sharing is one of the key aspects of diy. It can be both indirect through the seeking out and reading of instructions developed by others or more direct through the asking and answering of questions which is of benefit to both creators and readers (Kuznetsov, Paulos, 2010). Allowing 
for person to person expertise exchange is an important consideration that needs to be made.

\section{Precedents}

The following precedents (figures 1 - 11) were analysed based on three themes established in the previous section: documenting, recreating, and social engagement. Each precedent was chosen based on relevance to this research and similarity to the web application proposed by this research. 
Figures 1-3: Instructables Screen captures

(2016)

Instructables (Wilheim, 2005) is a website that allows for the documentation of any diy creations a user has created themselves and wishes to share. These creations range from house modifications to electronic devices and even how to guides for various activities. Users are able to comment on and review people's creations as well as 'favourite' them or save them into collections. Due to the general nature of instructables there is no specific category for diy assistive technology for the disabled. There are assistive technology and life hacks categories however they are for general use creations. 
Figures 4-5: Pinterest

Screen captures

(2016)

Pinterest (Sciarra, Silbermann, and Sharp, 2006) is a website that acts as a host to many types of content. In regards to diy, however, it allows users to collect various ideas and creations and store them within themed sections (called boards) within their own profile. These collections may be as simple as a series of images or more in depth like articles or sets of instructions. Users have the ability to save or 'pin' content they wish to keep, 'like' content, and leave comments. Due to Pinterest's 'boards' system there are many categories specifically aimed at assistive technology for the disabled. These 'boards' are easy to find through search and provide a reasonable variety of assistive technology, however, the information provided may not allow a user to adequately recreate any diy assistive technology they may find. 
Figures 6-7: Handihelp Screen captures

(2016)

Handihelp (Fabend, 2009) is a website setup by Rich Fabend in 2009. The website is comprised of diy assistive technology that he has developed himself. He has developed dozens of assistive tools that cover a reasonable amount of categories although these categories can be specific to his personal interests. The creations are displayed in a list format on the front page. 
Figures 8-9: Workshop Solutions Screen captures

(2016)

Workshop solutions (Jeary, Jeary, 1999) is a website created by Tom and Scott Jeary in 1999. The website was developed for "engineers, technicians, inventors and workshop enthusiasts" (Jeary, Jeary, 1999) to share diy assistive technology concepts they had developed. They provide 102 different examples that primarily aid with mobility and communication. 
Figures 10-11: Spinalistips Screen captures

(2016)

Spinalistips (Lagerkrans, Riedel, 2006) is a website created by Dorothee Riedel and Elisabeth Lagerkrans in 2006. It was created for the purpose of providing tips on how to alter objects or environments for people with spinal cord injuries. They provide hundreds of tips across two separate types of categories: activity based (housework, cooking, etc) and injury level (High tetraplegia without function in arms/hands, High tetraplegia with partial function in arms/hands, etc). Users have the ability to comment on tips. 


\section{Precedent analysis}

The five precedents described above each document diy assistive technology in some form. Some allow for communal sharing while others do not. In regards to the documenting process Instructables, Workshop Solutions, and Pinterest were the only three that had mechanisms in place for users to freely provide examples of diy assistive technology they had created. Each achieved this in different ways however.

In regards to documenting Instructables had the most robust and free system allowing any user with an account to upload their diy creations. Instructables also has mobile support. Documentation via a mobile device allows for the integration of the mobile devices features (e.g. camera) which can help create a more seamless documentation process due to each aspect of the documentation experience being integrated onto the one device. Pinterest achieves documentation through a method of content aggregation. This allows for users to freely upload content, however, they have no control over the information present within that upload. Workshop Solutions has a system in place in which users can email the owners of the site with their diy creation. They will then review it and then upload it themselves if they deem it appropriate. Spinalistips does not allow for users to freely upload content, instead they a have a small, pre selected user base in which they receive content from. Handihelp content is solely developed by the creator of the website. With the exception of Instructables, the above precedents all have somewhat convoluted processes (if at all) for documenting diy. This goes against recommended practice where a seamless process is adopted to improve user experience for creators and allow for more accurate documentation.

In regards to re creatability each precedent listed provides varying amounts of information. The most robust was Instructables which provided the stages to recreate each diy object in a step by step format featuring video and imagery. This format is open ended so whether or not the information provided by the user is process oriented is purely determined by the creator. There are no prompts of any sort from instructables to provide process oriented information either. The four other precedents don't provide information to recreate the diy objects they display. Each provide varying amounts of imagery however in regards to the information provided it tends to center around how to use the object, manufacturer information, and reason for developing 
the solution. Due to its nature of content aggregation, Pinterest can potentially show information on how to recreate the object but it's not certain so whether or not the instructions are process orientated cannot be determined.

Finally in regards to social engagement each of the five precedents feature indirect social engagement. They each achieve this by virtue of disseminating information for readers but also through their categorisation options and through providing authorship information. In terms of categorisation Spinalistips has the most robust system for accurately finding relevant diy assistive technology as they categorise by both task and disability while the four others categorise based on task or as a singular general category. While Instructables and pinterest have general categories they allow you to save creations into your account allowing for easy access at a later time. In regards to direct social engagement three (Spinalistips, instructables, and pinterest) of the five precedents provide the ability to comment directly onto the diy documentation while four of the five (Workshop Solutions, Handihelp, instructables, and pinterest) provide direct contact information for the author of the diy creation.

Of the the precedents that were analysed, Instructables was the most successful overall. This indicates that the web application being developed would be more successful using Instructables as the key precedent. Spinalistips, however, did have an interesting categorisation system which could be adapted within this web application.

Next, the demographics (older adults and people with stroke induced physical disabilities) established within the background chapter were analysed to help inform the creation of a set of heuristics. 
Persona development 


\section{Demographic}

Due to the majority of people affected by stroke being above the age of 65 , the finalised heuristics must be directed at this demographic. To help with this personas were developed to create a reference to multiple types of hypothetical users. There are multiple factors to consider when targeting users aged 65+: Experience using the internet versus expertise, cognitive difficulties, perceptual difficulties, motor deficiencies, (Hanson, 2009)(Becker, 2004)(Chadwick-Dias, McNulty, Tullis, 2004) and general user behaviour. (Shaffer, Williamson, 2002) (Boudreault et al, 2009)(Cohen, Will, 1985)

\section{Experience vs expertise:}

In this category experience is how much time a user has spent using the internet while expertise is their level of competence with the internet. In the case of older adults these two things don't always correlate. According to a study done by Chadwick-Dias, McNulty \& Tullis (2004) older adults tended to exclusively access the internet on home based computers in comparison to youths and younger adults who were more likely to access the the internet in more collaborative learning environments like school or work. This difference in usage environment results in a slower learning pace for older adults compared to younger generations.

Due to this lower overall level of internet expertise among older adults; issues arise in relation to interaction with user interfaces. It has been shown that older adults tend to be more careful with their actions, for example, reading information thoroughly before deciding whether or not to click a link. Older adults also can have trouble establishing pre defined patterns on the internet like establishing whether or not something (headers, icons etc) is a link. Older adults also can struggle to understand terminology common to the internet like 'back' or 'home' etc. (Chadwick-Dias, McNulty, Tullis, 2004)

\section{Cognitive difficulties}

Older adults face one primary issue in regards to cognitive difficulties in relation to internet usage: This issue is associated with what has been termed fluid intelligence (Hanson, 2009). Fluid intelligence refers to short term memory, the speed at which we process thoughts, and our ability to reason ab- 
stractly. With age these processes decline along with our ability to identify details amongst distractions (Becker, 2004). The decline of fluid intelligence can make internet navigation and the learning of new internet technologies particularly difficult. Cognitive disabilities in regards to stroke (aphasia etc) are not being considered for this research.

\section{Perceptual difficulties}

Older adults see a decline in both hearing and vision as they age, of the two however, vision has the greater affect on a user's ability to interact with the internet. As a person ages a few problems arise in the eye: elasticity of the lens degrades resulting in a worsened ability to focus on close objects, visual acuity also declines resulting in a worsened ability to see objects clearly, colour perception is affected due to the eye's lense yellowing and thickening, and light sensitivity, contrast discrimination and depth perception also decline. These issues culminate in difficulties with reading "small text, text that is closely surrounded by other visual elements, and text that has complex font styles or lowered contrast due to poor color choices on pages" (Hanson, 2009, p8) as well as discerning visual elements on patterned backgrounds. (Hanson, 2009)(Becker, 2004).

\section{Motor deficiencies}

Older adults often see decline in motor skills as they age which is even more exacerbated by the onset of stroke related disability. This decline can result in more time being taken to complete movements and those movements being less smooth and precise. This decline in motor skills can make operating a mouse and keyboard difficult and clicking on small screen elements and scrolling difficult. (Hanson, 2009)(Becker, 2004).

\section{User behaviour}

To further develop the personas, user behaviour specifically focused on people post stroke was considered. Three general categories were established from literature: Ability to perform activities of daily living, social participation, and social support. (Shaffer, Williamson, 2002) (Boudreault et al, 2009) (Cohen, Will, 1985). 
The commonly used categories of activities of daily living include but are not limited to nutrition, fitness, personal care, and communication (Boudreault et al, 2009). Shaffer and Williamson's (2002) ARMDA (Activity Restriction Model of Depressed Affect) proposes that the degree in which activities of daily living are restricted directly corresponds to a person's ability to adjust to chronic illness. ARMDA suggests that chronic illness and disability act as life stressors and have a direct impact on depression forming within the affected individual. Activities of daily living are proposed to act as a mediator between the two and that through maintaining some degree of normality depression can potentially be prevented.

Social Participation is succinctly summarised by the Disability Creation Process (DCP) model. The DCP is used as a predictor for social participation based upon two categories: Personal and environmental. Personal factors include organic systems (e.g. respiratory, digestive, muscular systems) and capabilities (e.g. intellectual, language, motor activity capabilities). The environmental factors refer to social (e.g. health, and educational systems, social network) and physical (e.g. nature, architecture, technology) systems. Through the interaction of these personal and environmental factors a list of twelve 'life habits' is generated. These 'life habits' form two categories: Daily activities and social roles. The six attributes for daily activities are nutrition, fitness, personal care, communication, housing, and mobility while social roles six categories are responsibility, interpersonal relationships, community life, education, employment, and recreation. Through these 'life habits' social participation can be predicted. (Deaudelin et al, 2007). Daily activities influence the social roles by acting as prerequisites (Boudreault et al, 2009).

Lastly, social support, according to Cohen and Will's (1985) Stress, Social Support, and the Buffering Hypothesis can be assessed based on the buffering model. The buffering model states that stress is alleviated through social support that is responsive to the needs associated with the origin of the stress. The types of support outlined are esteem support ("information that a person is esteemed and accepted"(Cohen, Will, 1985, p 313)), informational support ("help in defining, understanding, and coping with problematic events"(Cohen, Will, 1985, p 313)), social companionship ("spending time with others in leisure and recreational activities"(Cohen, Will, 1985, p 313)), and instrumental support ("the provision of financial aid, material resources, and needed services"(Cohen, Will, 1985, p 313)). Each of these support types are not independent and interlink based on the cause of stress on an individual. 


\section{Personas}

Based on the demographic information established, four personas were created to help develop the heuristics and assess the user interface as seen in figures 12-15. 

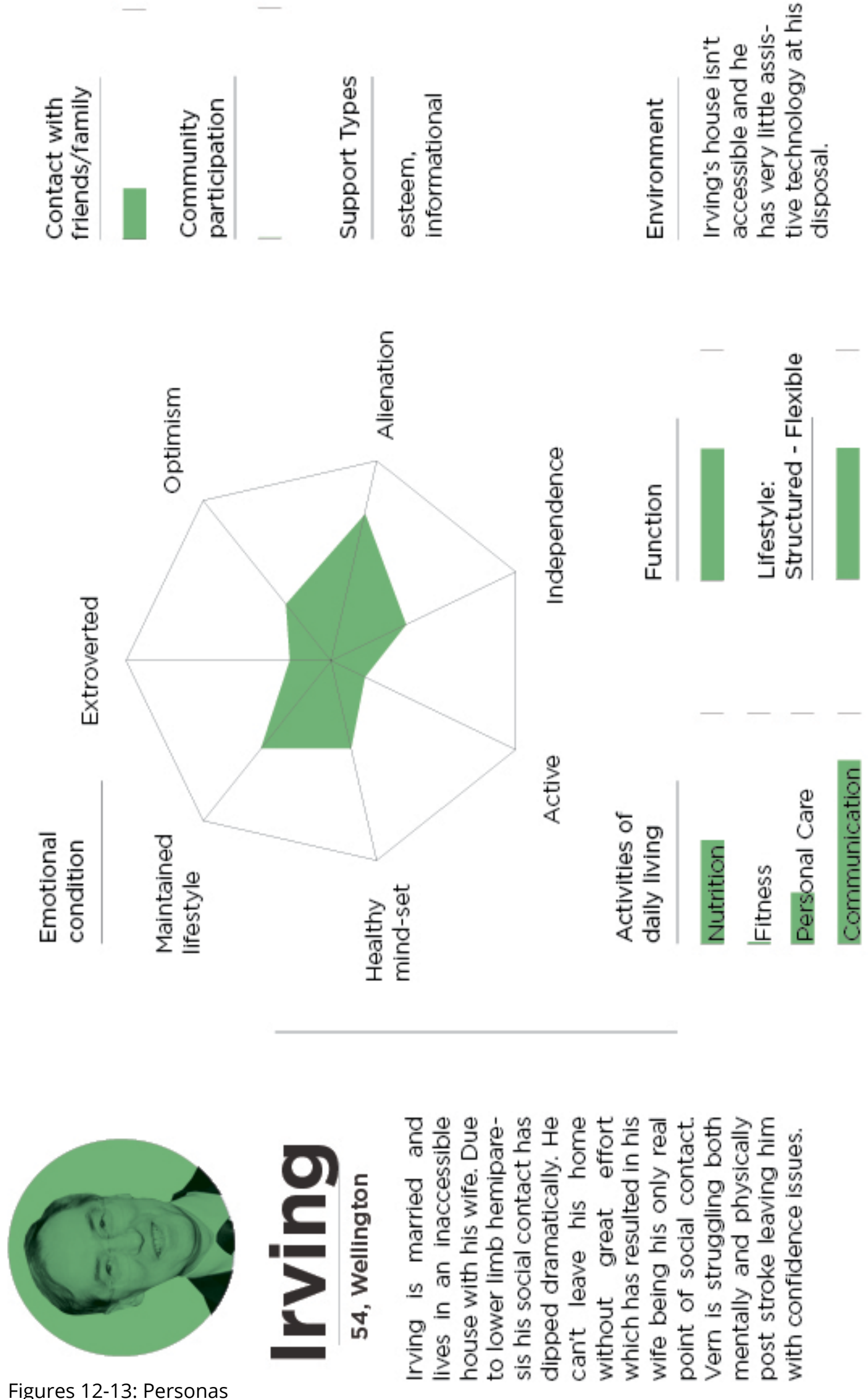


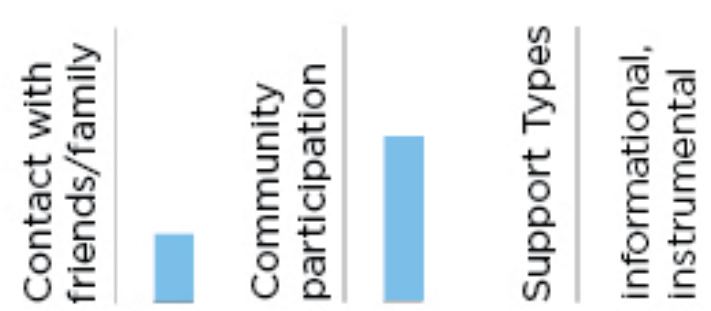

$\stackrel{\frac{4}{d}}{\subseteq} \frac{\dot{4}}{\omega}$

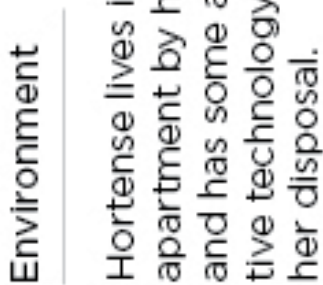
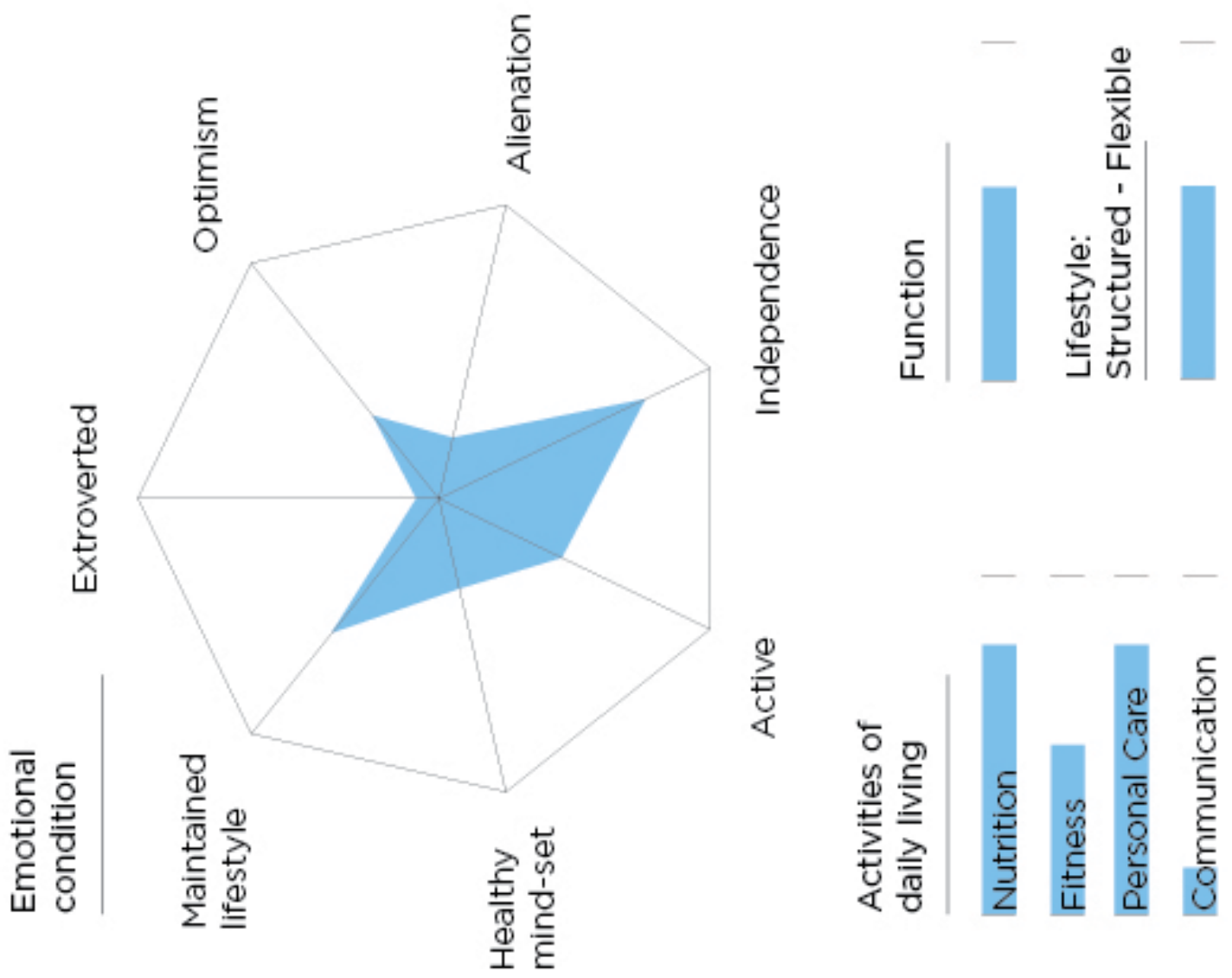

$\sum_{\substack{4 \\ 4}}^{1}$
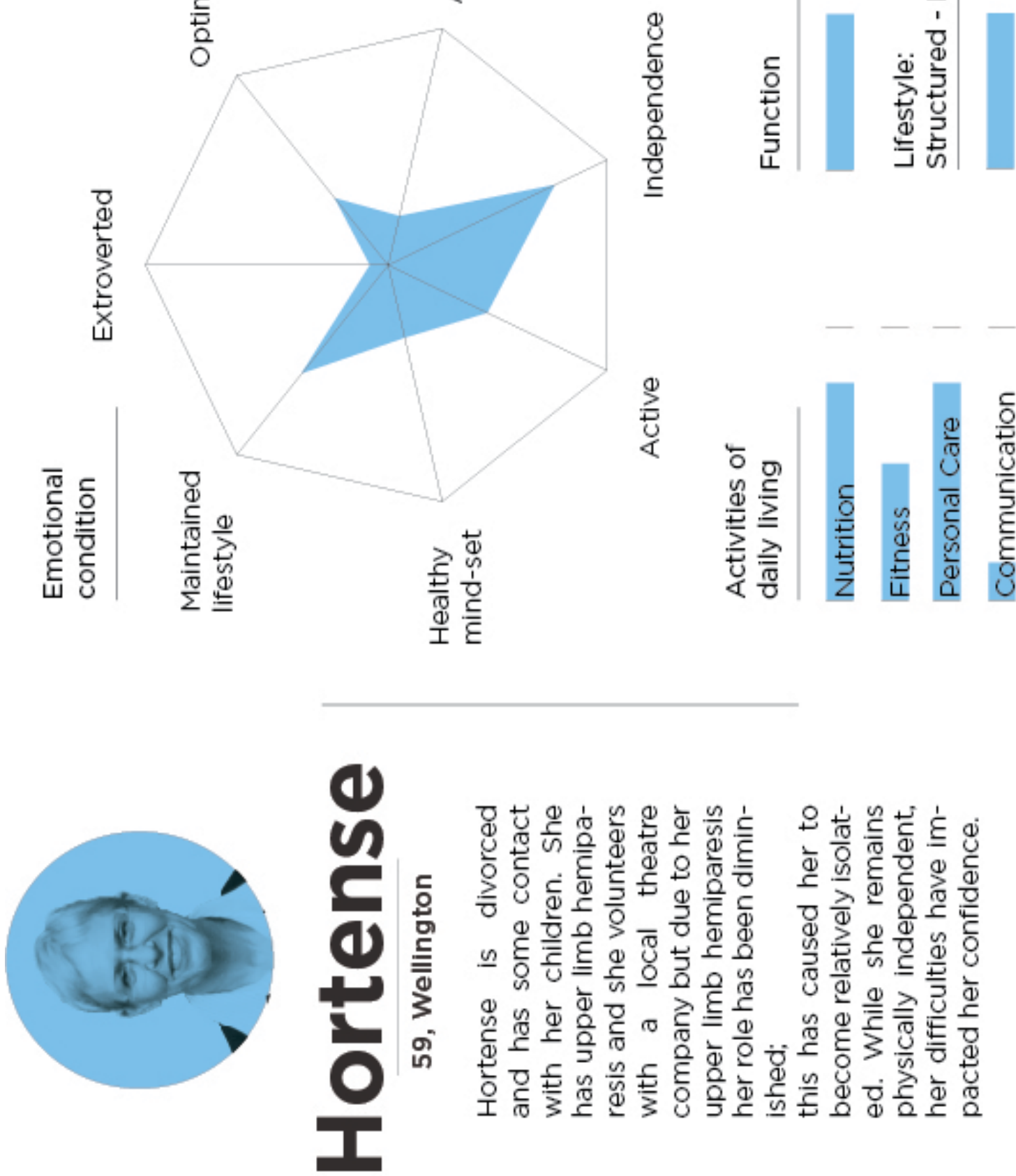

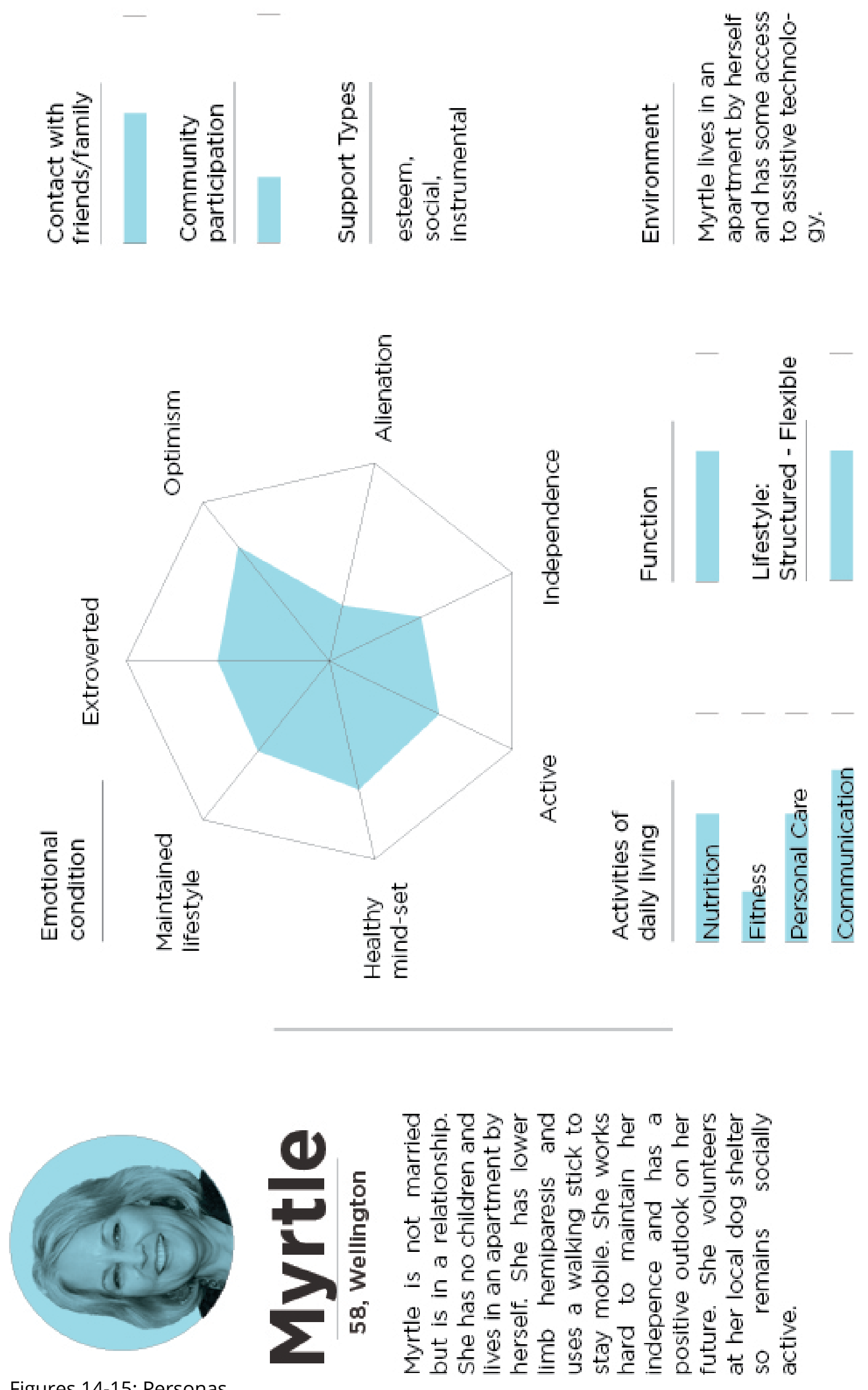

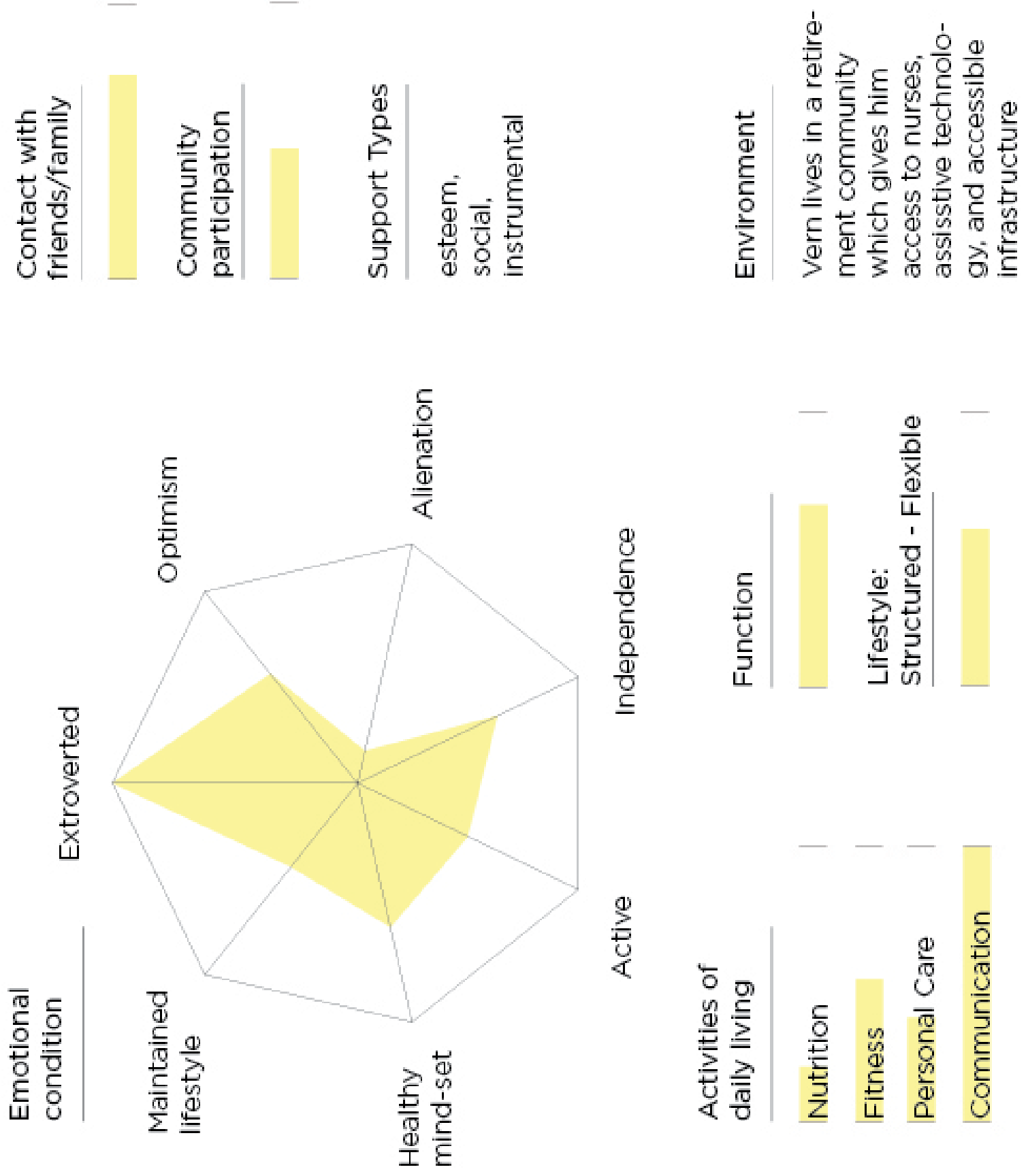

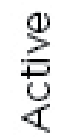

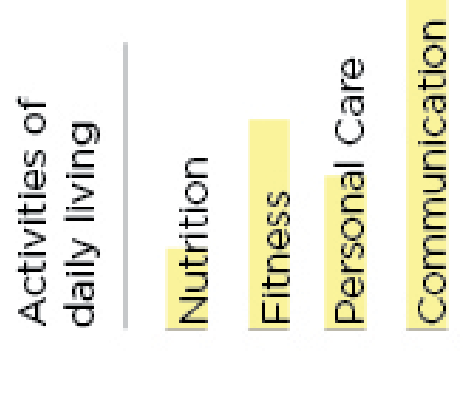

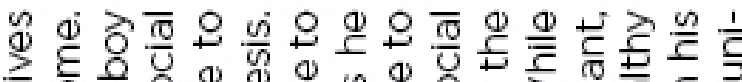

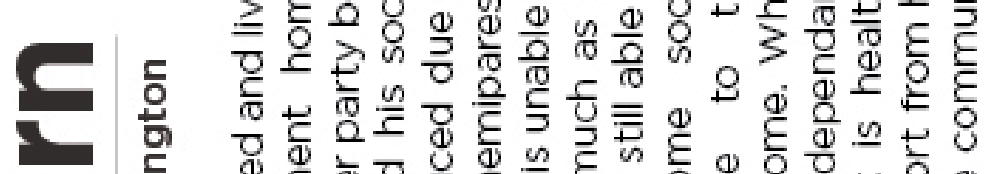

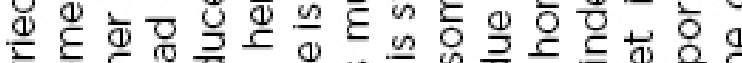

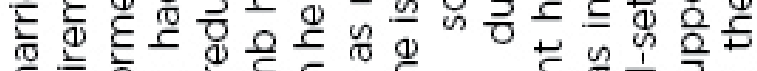

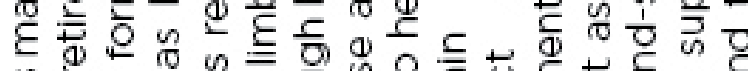
此穴

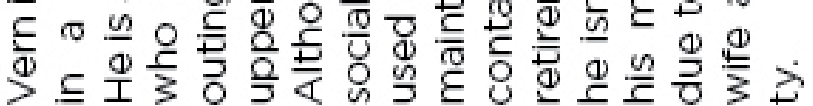


Heuristics 


\section{Technical}

The final step required to develop a set of heuristics is the consideration of the technical side to the use of this web application. This includes the device that will the user interface will be designed for and accessibility requirements established by the New Zealand Government.

\section{Device selection}

This web application will be designed for use on a handheld device (a tablet or a smartphone). The primary reason handheld devices have been targeted is according to a study done by Research New Zealand (2015), 51\% of adult New Zealanders own a tablet and $70 \%$ of adult New Zealanders own a smartphone with each demographic growing rapidly allowing for a wide audience. $86 \%$ of smartphone users regularly access the internet on their device with social network use being the primary reason. In regards to older adults specifically, internet use is primarily with pc (54\%)/laptops (53\%) although feature phone closely trails with $47 \%$, smartphone usage is $45 \%$, and tablet usage is $39 \%$. Although pc/laptop usage numbers are higher, handheld device use is growing rapidly with a $20 \%$ plus rise in usage for smartphone and tablets between 2013 and 2015. The secondary reason is the feature integration on handheld devices is well suited to the purpose of the web application. The two features primarily used were as follows:

- Wifi: Necessary to establish a connection to the web applications servers.

- Camera: Used during the documentation process to record the development process.

\section{New Zealand web accessibility standards}

Web Accessibility standards set by the New Zealand Government were considered in the development of heuristics. Nine aspects of web design have been outlined for consideration when creating websites (New Zealand Government, 2016):

- Text alternatives: Alt tags on text must be correctly implemented for screen reading devices. 
- Adaptable: The correct html must be used for structural and functional components, page hierarchy must be understandable without styling, and icons must have accompanying text.

- Distinguishable: Colour used in a meaningful way must be reinforced using other methods and appropriate contrast must be applied, and text must not be inserted as an image.

- Enough time: If a time limit has been placed on any function within the web application there must be an option to turn off or adjust that time limit, and moving, blinking, scrolling, or auto updating content must have an option to be paused stopped or hidden.

- Seizures: Content must not flash more than 3 times a second.

- Navigable: Each page has a unique, descriptive title tag, each link's purpose is identifiable based on its own context, multiple methods of site navigation, and headings accurately describe the content beneath them.

- Predictable: When an on screen element gets focus or has its setting changed (radio button, drop down menu) it mustn't change its context in any way, repeated elements must maintain their order and visual consistency.

- Input Assistance: Include error messages when users incorrectly fill out forms, form fields are appropriately labeled, and allow for users to review forms before submitting. 


\section{Heuristics}

The following nine heuristics were developed based upon the prior precedent analysis, demographic analysis, and technical considerations. Jakob Nielson's (1994) ten usability heuristics for user interface design were used as a base. Nielson's ten heuristics are a highly developed and thoroughly tested set of usability heuristics designed to broadly encompass a wide array of issues that arise in the development of user interfaces. Nielson's ten heuristics were, however, altered accordingly to more accurately reflect the knowledge that was acquired.

1) Simplicity: Don't overcomplicate - one or two actions per page.

2) Clarity: Make required actions or options as clear as possible.

3) Memory: Make sure the user has to remember as little as possible.

4) Customisation: UI elements.

5) Accessibility: Meet online accessibility standards.

6) Familiarity: No jargon - speak users language.

7) Control: User stays in control at all times.

8) Consistency: All introduced elements must have one meaning only.

9) Flexibility: Allow for accelerators for experienced users. Don't rigidly force a process unless necessary. 


\section{The concept}

The concept is a web application that acts as a communal database of diy assistive hacks. The web application is an extension diy and of non-intentional design (Brandes, 2008). An example of this, within the context of this web application, would be using a tennis ball as an alternative hand grip for a pencil or pen. Users will engage with this web application by posting their own DIY assistive creations (like the tennis ball example) for the creation and use of by other users. Coupled with this will be the option to create an ability profile. This ability profile will allow a user to create a summary of their physical function so that they may have access to hacks that directly impact them.

For example, imagine a man by the name of Chuck. Chuck has had a stroke and has lost fine motor skills in his right hand due to upper limb hemiparesis. Chuck likes to draw but can no longer hold a pencil well enough to do so. He finds the web application, creates an account and with it an ability profile, this leads him to the tennis ball example mentioned above. With the help of his wife he follows the instructions and creates the hack which allows him to draw again. 
Technical development 


\section{Development}

The following section details the technical process of creating the web application. This includes requisitioning a database, normalising tables, security, and the front end considerations.

\section{First steps}

The first step taken during the design phase of the web application was establishing the back end of the web application. Two key actions were taken to achieve this: storage of text within a relational database and storage of imagery within a separate database.

In order to allow a user to have a profile, create diy documentation etc a method of remote text storage must be implemented so that the web application can access this information from any location. Initially this was achieved through the use of javascript (a programming language that operates within a web browser) and JSON (JavaScript Object Notation (a text format that can be read and processed by machines)) stored on a plain text file that was stored in a remote server. This method of data retrieval was flawed, however, for two core reasons: the first being that security of the user's information was weak at best and the other reason being that each time the web application refreshed the browser would need the empty its cache (temporary storage of files) and redownload the entirety of the information stored regardless of it's relevance to the user resulting in increasingly long load times as the amount of data stored increased.

Due to these issues an alternative direction was taken; The services of heroku were used. Heroku is a free cloud based platform that allows for the hosting of web applications. Heroku has a postgreSQL (an object-relational database management system) based relational database service that was used to store information from the web application. On top of this PHP (a programming language that operates within a server) was now used to communicate with the relational database. PHP was chosen due to my own familiarity with the language and because heroku has extensive support for it. 


\section{Normalising the database}

Relational databases that store text do so within tables. These tables are like spreadsheets with rows and columns which need to be organised in such a way that relevant information is stored together. Once the relational database had been established tables needed to be created within it to store the relevant information in an appropriate manner. To achieve this database normalisation was used. Database normalisation is the act of organising the columns of each table in such a way as to reduce data redundancy. This process may result in the splitting of tables into a larger number of tables that hold less information and make use of keys that keep relevant data linked. The purpose of this is so that when data is inserted, modified or deleted it only needs to be done so in a single table instead of multiple.

The finalised relational database for this web application used a total of nine tables to store user data as seen in figure 16. Two keys were used to link relevant data across tables: userID and hackID. 


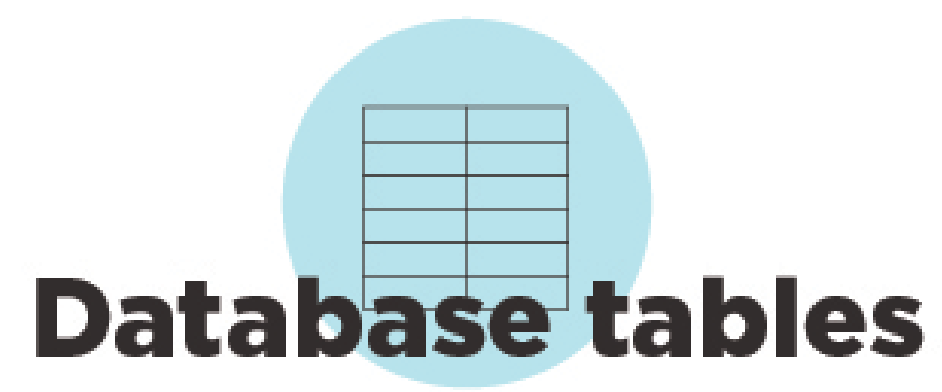

hacksGeneral

| hackID | herolmageURL | type | description | userID |

hacksSupplies

| hackID | supplyNo | item | altıngredient |

hackTips

| hackID | tip |

hackInstructions

| hackID | stepNumber | stage | instructions |

userProfile

| userID | username | password | firstN | lastN | proPicURL |

userFollowing

| userID | following 


\section{Security}

In regards to security, only one issue was primarily focused on due to time constraints: SQL injection. SQL (Structured Query Language) is a programming language designed specifically with the purpose of managing and manipulating data within relational databases. SQL injection is the act of inserting lines of SQL code into a relational database table through input methods (usually form fields e.g. username) in a web application. These SQL code snippets are linked with standard input strings (e.g. the user's username) so that when they are stored within the relational database table the code is executed. This is a serious security issue because it allows the information stored within relational databases to be manipulated by anyone. SQL injection was prevented through the use of two methods used in combination: escaping strings and prepared statements. Escaping strings is the act of reducing the ambiguity of special characters (quote marks for example) so that unintended actions aren't taken by a computer. This helps to prevent SQL injection by helping solidify a string so it is read as a whole and not as a string then an SQL code snippet. Prepared statements are an efficient method of repeatedly sending data through to a relational database. Prepared statements prevent SQL injection by stopping data from being copied directly from an external input source making it so SQL injection cannot occur.

\section{Imagery}

The final consideration that needed to be made in regards to the back end was storage of imagery. Amazon s3 (simple storage service (a cloud based file storage service)) was used to do so. Amazon s3 was chosen due to it's ease of use and support for php. The main considerations that were made when creating the upload process were based around file restrictions. Firstly the file's mime type (file type) was checked to determine if the file was an image. Next, the specific file type was checked to determine if the image was either a jpeg, png, or gif. Lastly, the file's size was checked to determine whether or not it was under $5 \mathrm{mb}$. This is a high ceiling for file size, however, due to the user being able to upload photos directly from the camera on their device it was necessary.

\section{Front end}


To develop the front end of the web application html, css, and javascript were used. Html was used in combination with php to populate the web application with information and also send information through to the relational database. Sass (a css preprocessor and extension of css) was used to write css. Jquery (a javascript library) was used for event handling and html and css manipulation.

The following details some specific front end requirements of features within the web application:

Cookies (small dataset stored within a browser): The bookmark feature required the reading and saving of cookies to the browser. When a user selects a piece of diy assistive technology the identification number of the assistive technology is saved to the browser's cookies so that if the user selects the bookmark option then the information from that cookie is sent to the relational database. The login, logout, and register features also required the use of cookies. Login required the saving of a user identification number into a cookie so that each account dependent section within the web application could be correctly populated with information from the relational database.

Text resizing: REM units were used to determine text size within the web application. REM units are a measurement unit that determines size based upon a root value. Once the root value is altered, all other text using REM units is altered accordingly. 


\section{Design process}




\section{User Interface}

The following section details the process of developing the user interface. This process begun by developing a Minimum viable product for the home screen, navigation, documentation screen, create screen, and user flow. After the initial framework was established the user interface concepts were evolved and expanded to include the profile screen, settings screen, and personal diy screen. From there a user interface and user flow was further established and a heuristics review was performed. Once the user interface and user flow were finalised aesthetics were developed and implemented in preparation for user testing.

\section{Minimum viable product}

The first step undertaken in developing the user interface was establishing a user flow and page content. The reasons for this being: It allowed for the initial page order to be established, initial user onboarding to be established, the initial content of those pages to be established and how it was ordered, and initial features to be brainstormed.

To begin page order was established. The page selection was purposefully kept simplified to the web applications core elements: home screen, documentation screen, and the create screen. The reason this was done was to develop a minimum viable product ( $m v p$ ) for the web application before expanding. The first user flow developed for these core pages coincided with development of the first onboarding process (figure 17). This process began with the user beginning on a home screen and then allowed the user to log in, create an account, select and expand documentation or create diy of their own. This process was decided upon based on 3 heuristics: simplicity, memory, and control. Simplicity because because older adults more commonly have lower expertise levels in regards to operating user interfaces so tend to more thoroughly consider their options (Chadwick-Dias, McNulty, Tullis, 2004) so the assumption was a simplified set of options eases that process. Memory for reasons similar to simplicity, to reduce the cognitive load on older adults due to declining fluid intelligence (Hanson, 2009). Lastly, control because having access to each page be at most two steps away or preferably one aided with memory load in that less navigation paths had to be remembered by the user. 


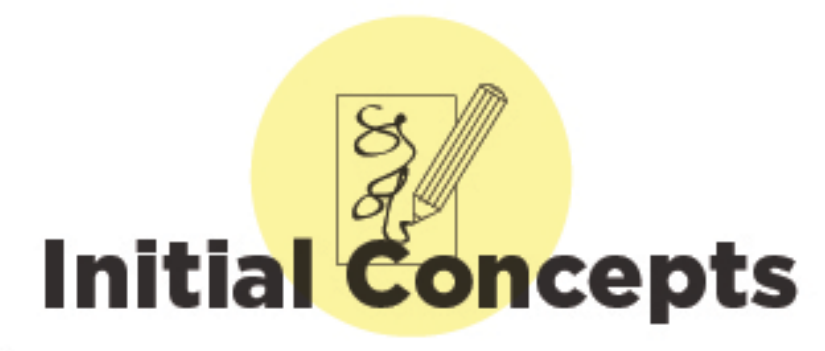

\section{User Flow}

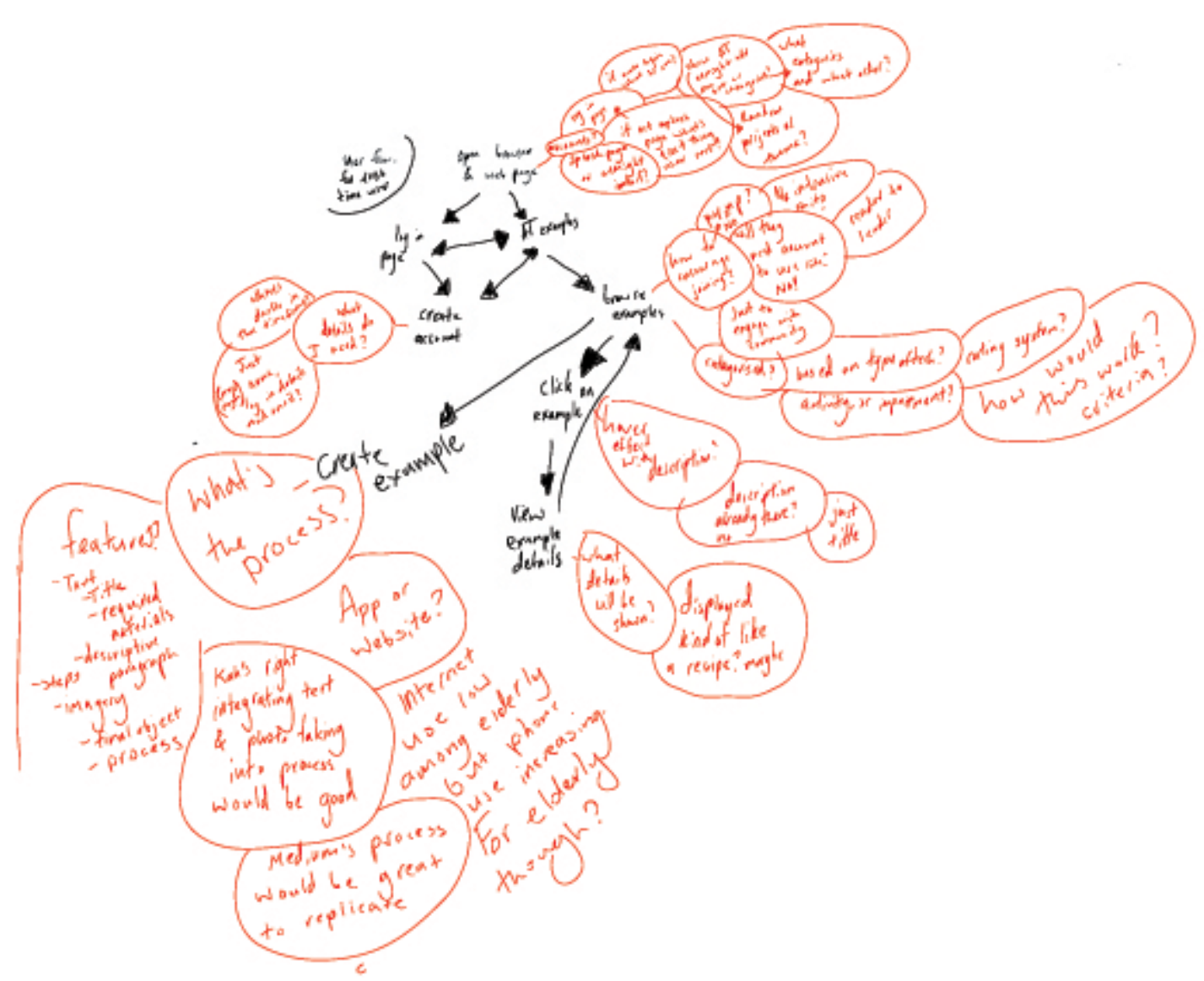

Figure 17: Concept sketches 
Next the contents of the mvp pages were established:

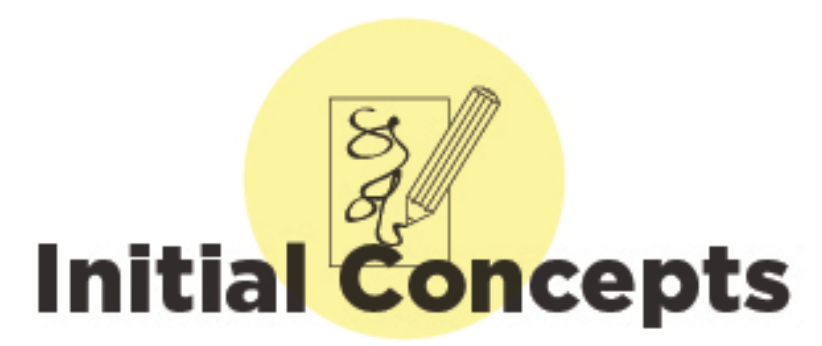

Home Page

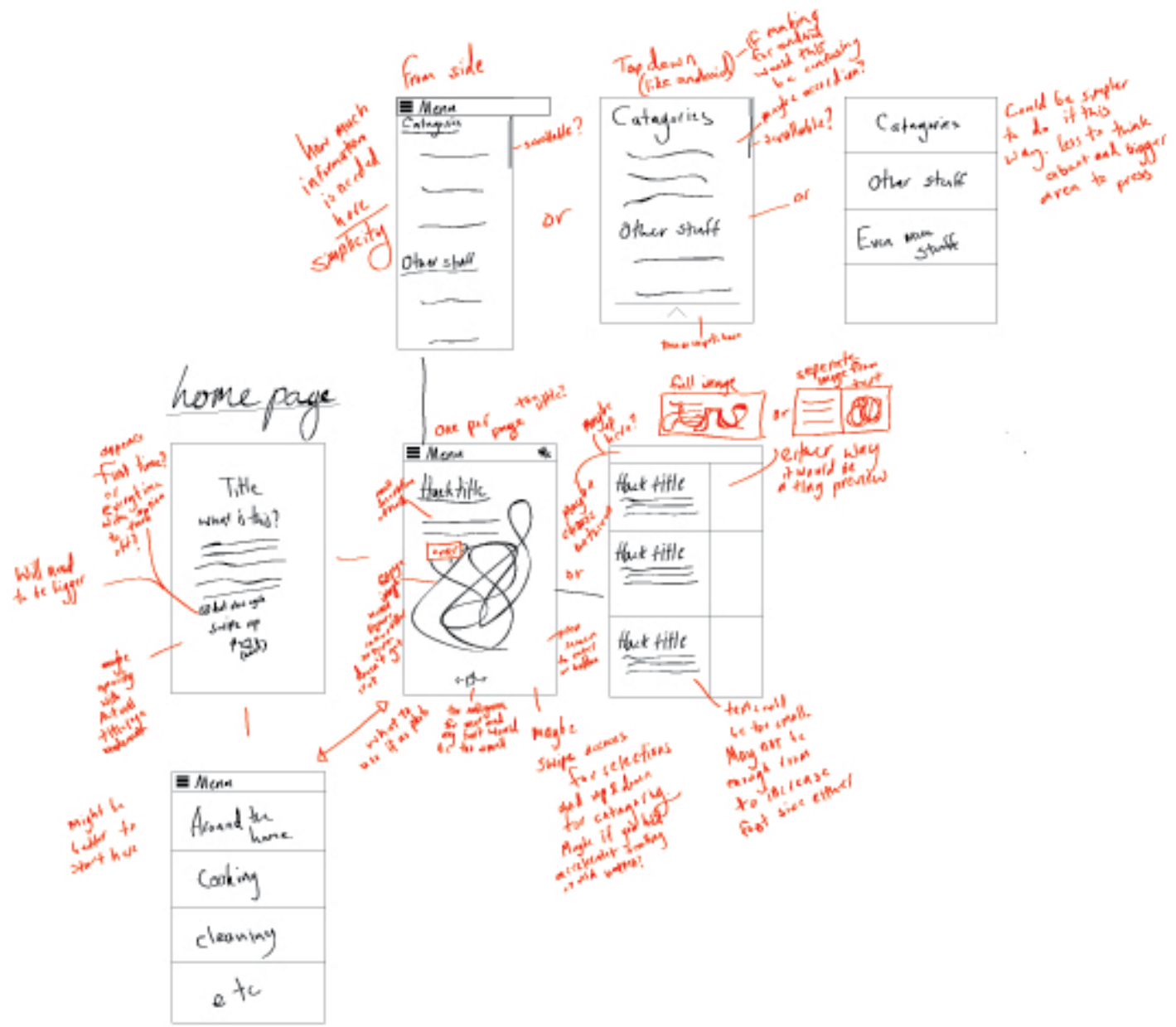

Figure 18: Concept sketches 
Initially the contents of the homepage was going to be a list of the current available diy creations hosted on the web application. This decision was made for two reasons: The first being that this page would would have access to each mvp page (coinciding with the control heuristic), and the second being that the core focus of the web application is dissemination of diy assistive technology so making that the first visible thing seemed logical. In order to facilitate onboarding, a screen overlay would appear for first time users giving a brief description of the web application and potential first steps for users to take once the overlay is closed.

In regards to layout, the available diy had two options in how it was going to be displayed: The first was to have a fullscreen overlay of the hero photo of the diy creation with text overlayed; the other was to have a section one third the height of the screen with the hero photo in a square on the right side and the text on left side. Of these two options the full screen overlay was chosen as it embraced the heuristics more fully; in particular simplicity and accessibility. Simplicity because older adults can struggle to identify details amongst distractions (Becker, 2004) so simplifying the amount of information on screen to a single diy creation seemed logical. Accessibility because it allows for larger text to be used and more spaced out as older adults tend to have degraded vision making reading difficult (Hanson, 2009).

Navigation was the last element of the home screen that was considered. A fairly generic approach was taken initially with a simple navigation bar and sandwich icon. The generic route was taken because the way the menu options were presented was more important. The menu was initially reduced to being diy categorisation information, login options, and create. They were presented in sections one third the size of the screen so text could be large to coincide with the accessibility heuristic and when selected they expanded out to display the matching information. This method of navigation was chosen due to the simplicity and clarity heuristics. Due to the lessened expertise of older adults, it seemed logical to reduce the amount of options at each stage during navigation 


\section{Initial Concepts}

\section{Diy Creation Page}

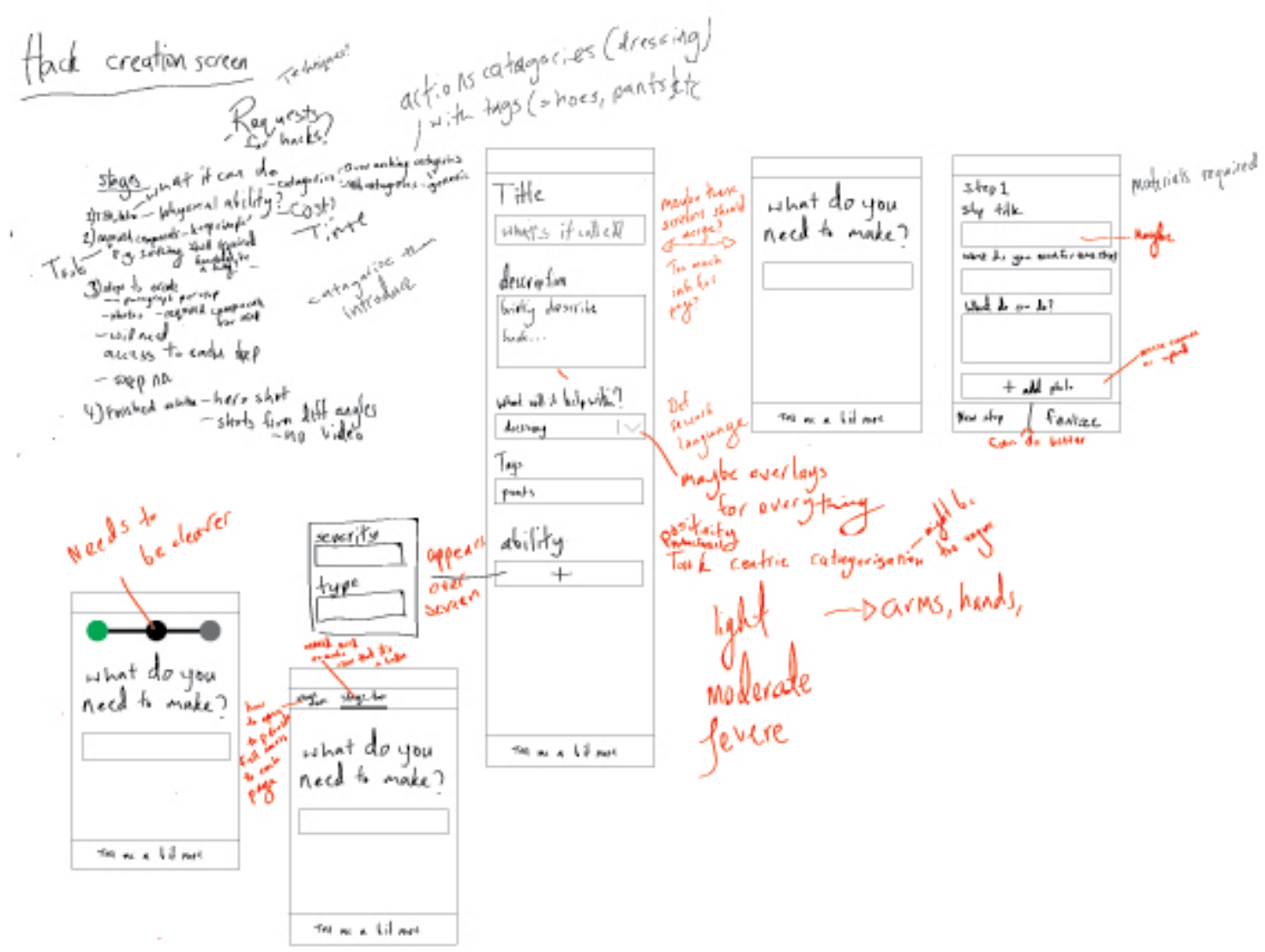

Figure 19: Concept sketches

The first step taken to develop the diy creation screen was to establish the most appropriate information required from the user when documenting their creation. In accordance with the plan of initially developing the minimum viable product the core information required to recreate the diy object 
was first established before expanding. This information was established as: categorisation information, title, a brief description, the tools and materials required to create the object, the steps required (each step would have a description and a photo), and a photo of the finished object. Next the categorisation information was decided upon.

The categorisation information had three parts initially. The first was based on the four activities of daily living categories identified in the user behaviour section: Nutrition, fitness, personal care, and communication (Boudreault et al, 2009). These were chosen to help the user narrow their search based on where the problem was occurring. The second categorisation option was three tags (single words related to the activities of daily living). This option was chosen in order to help the user be more specific in regards to where and what the problem was. Lastly, the third categorisation option was the type of post stroke physical disability it catered to the most. This was in relation to the ability profile that was created for use by a user. Two options were included here: the first was severity (light, moderate, severe) and the second was type (lower limb hemiparesis etc). This was chosen to help filter the diy shown to the user based on the information accumulated within their ability profile.

It was then decided that this information would be laid out across multiple pages. This would mean the user would be required to fill out the form in a step by step process. To mitigate the clash with the control heuristic a navigation bar was placed at the top of the screen so the user would be able to navigate back to previously filled out sections. This step based process was chosen due to the simplicity heuristic and wanting to lessen the information presented to the user. The decision was also made early to have headings for the forms be conversation like in nature. This decision was made based on the familiarity heuristic. Due to lowered internet expertise levels amongst older adults common terminology isn't always understood. (Chadwick-Dias, McNulty, Tullis, 2004)

The last consideration was the order the information would be presented in. As was established previously, creators tend to want a seamless experience for documenting their creations (Tseng, Resnick, 2014) so the order was based off the assumed building process. Introduction (title, description) and categorisation information came first, material information, step information (how ever many steps that are needed), lastly a photo of the finished object. 


\section{Initial Concepts}

Documentation Page

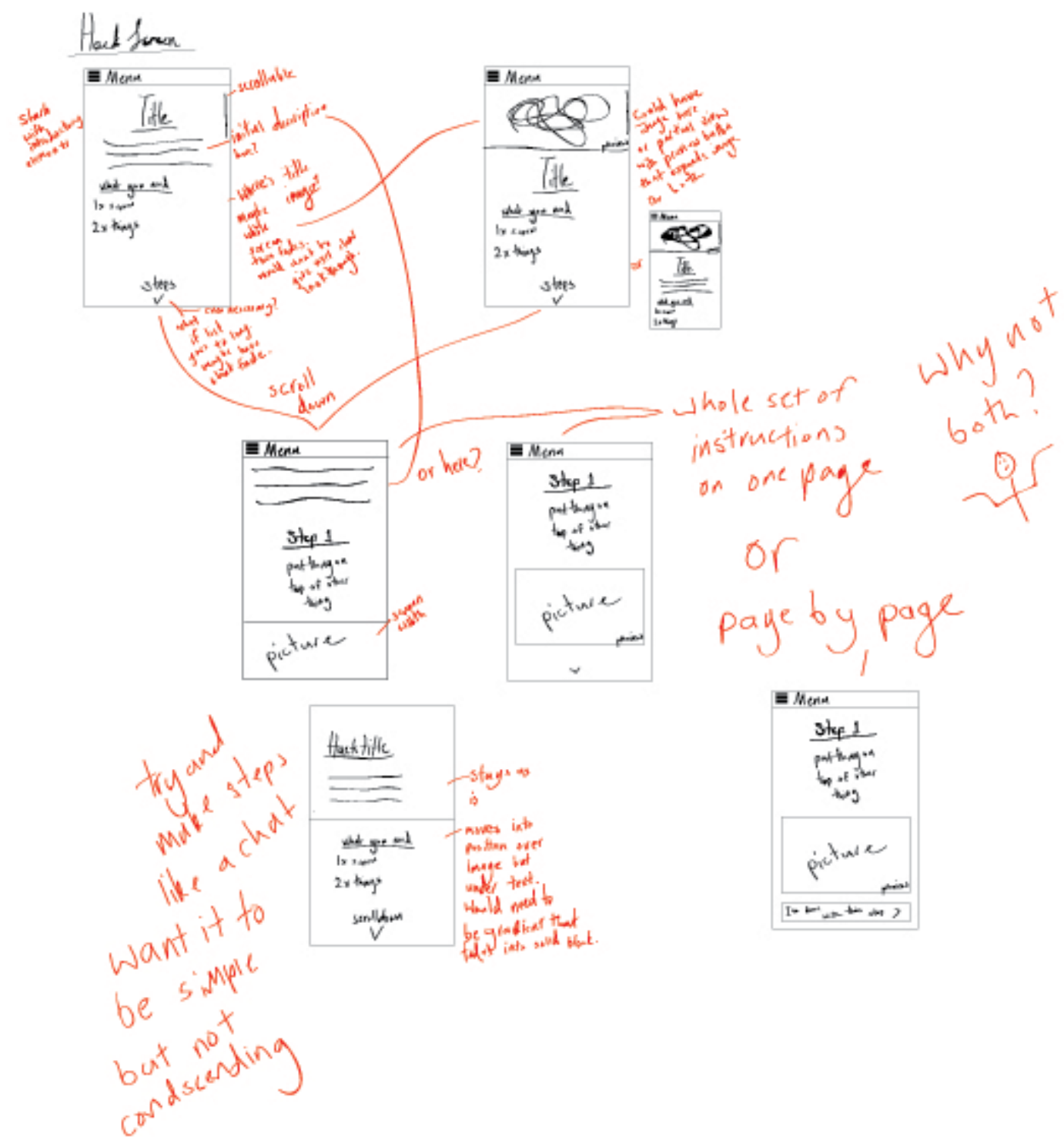


The documentation page was developed after the diy creation page purposely. This is because once the required information (in regards to the recreation of the diy object) had been established the main task was to order said information in a logical manner. The first decision in this process was whether or not to have the documentation displayed in page based format or as a single, scrollable page. A single page format was chosen due to the control heuristic. This is because a single page would allow easy, quick access to any part of the documentation the user needs as users tended to use documentation as a reference rather than a strict guide (Tseng, Resnick, 2014). The information for the documentation section was ordered in such a way as to match the assumed building process for a user. Introduction information (title, description, categorisation information), material information for the initial gathering of supplies, each available step for the building process, and the username and photo of the user who created the object. 


\section{Expansion}

Once the minimum viable product was established the user interface was expanded to include a profile screen, settings screen, and personal diy screen. Before these three pages were included however the documentation, diy creation, and home screens were readdressed and further developed.

\section{Changes}

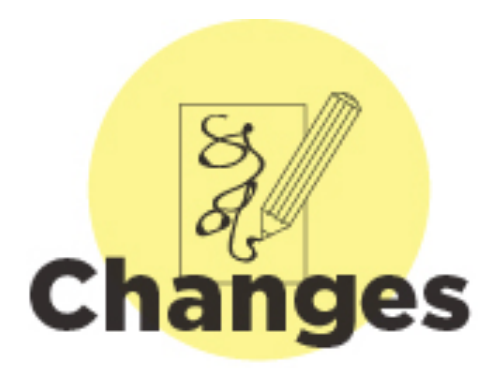

\section{Homepage}

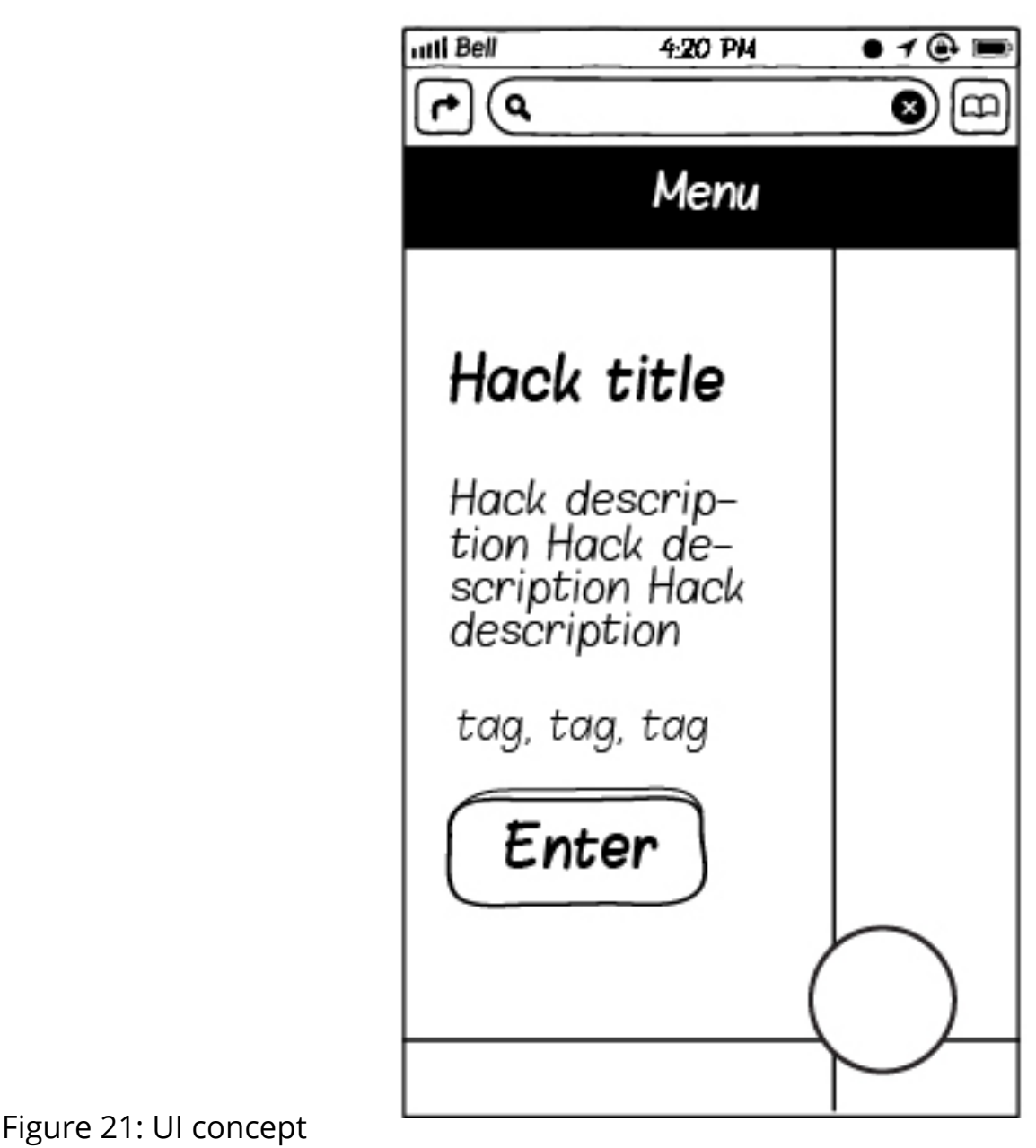

Figure 21: Ul concept 
The homepage faced four changes: The first was minor and was a repositioning of the text over a rectangular section two thirds the width of the screen. This was done to show the finished image more clearly so the user would have a better idea of what they would make. The second change was the addition of a button in the bottom right corner of the screen that linked to the create diy screen. This was based on the flexibility heuristic and was done to allow quicker access to one of the core features of the web application. The third change was to the navigation. The menu bar remained however now held three screens (profile, settings, user diy) with a second navigation bar inside positioned at the top of the screen instead of having the text based menu appear. This was done because with the inclusion of the three new screens it felt necessary to limit the amount of screen swapping (having fewer steps between each screen) as much as possible. This change to navigation clashed somewhat with the clarity heuristic in regards to clearly stating to the user where they were navigating too, however, to correct this the accessibility heuristic was followed by having headings that accurately describe the content beneath them (New Zealand Government, 2016). This was also mitigated somewhat because there are only a small amount of pages within the web application. The final change was to the length of the diy creations shown on screen. Due to diy creations being the full length of the screen there was no indication to the user to scroll. This went against the clarity heuristic so in order to correct this each diy creation had its height shortened to eighty percent of screen height so the top of the diy creation would show below it. This indicated to the user there was something to scroll down to. 


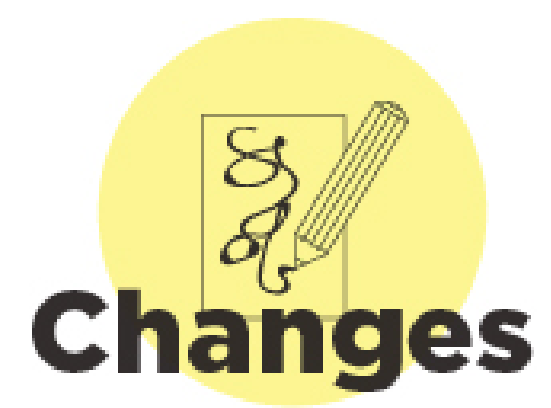

\section{Diy creation page}

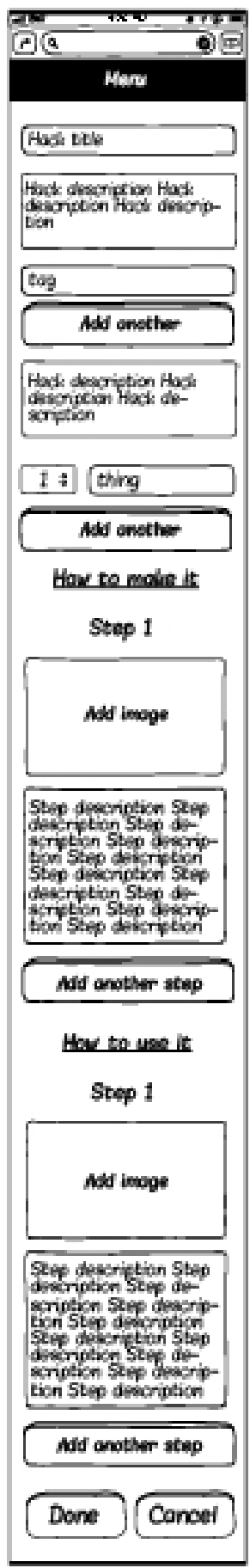

Figure 22: UI concept 
The diy creation page saw one changes: It was changed to a single page form. The main reason a multipage form was used was to conform to the simplicity heuristic, however, by doing so there were clashes with the control heuristic. The navigation element wasn't solving the issue of the clash successfully so the change to a single page form was made. One other change that was heavily considered and briefly inserted was the inclusion of having the user state how to use the object in a step by step format. This was done because usage information is important especially in the case of complicated diy however this did clash with the flexibility heuristic in that it was forcing an unnecessary process on the user. 


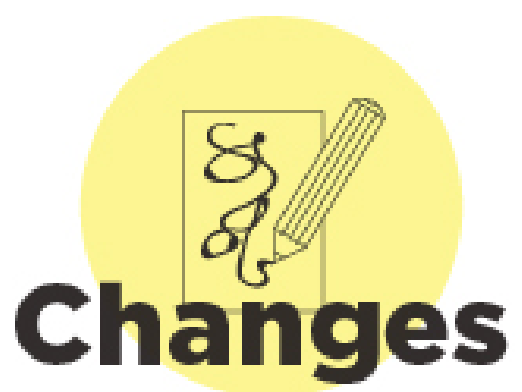

\section{Documentation page}

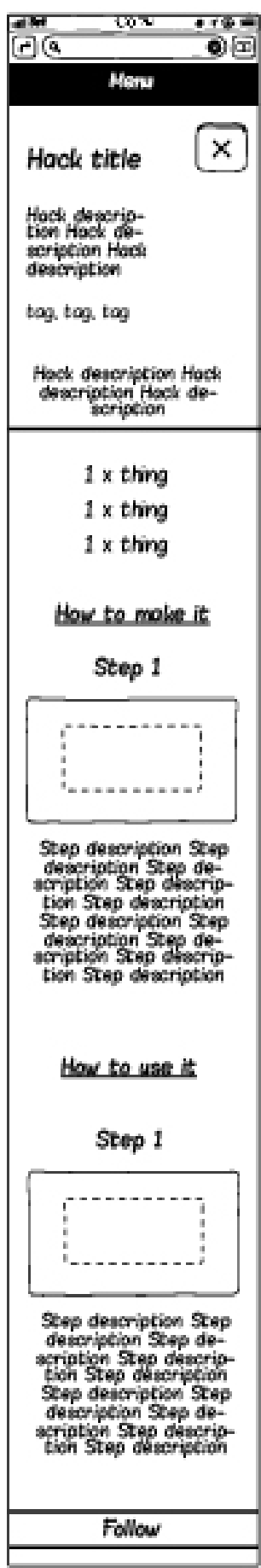

Figure 23: UI concept 
The only change made to the documentation screen was the inclusion of the briefly included how to use information. This was positioned underneath the how to build information in order to conform to the assumed building process. 


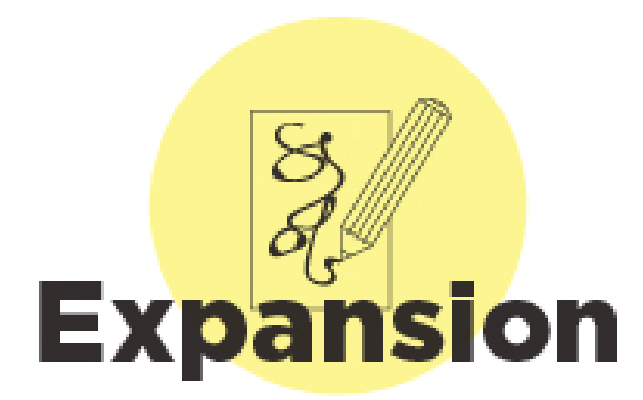

\section{Profile page}
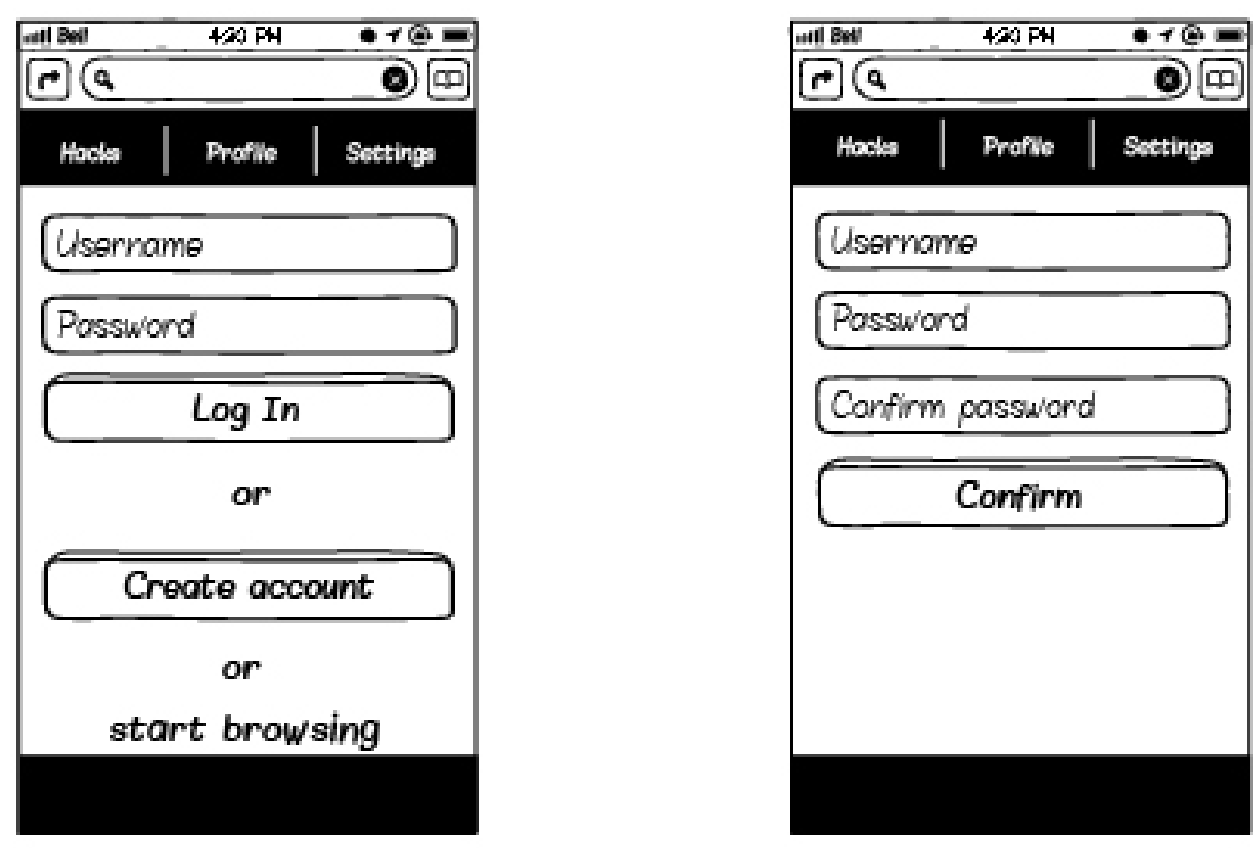

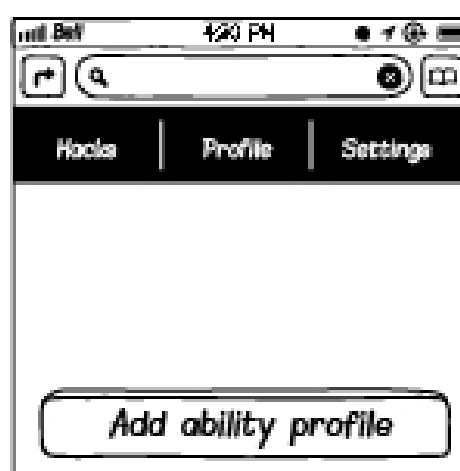

You can add this now or do it later.

Figure 24: UI concept 
The profile page contained three states that had to be considered: not logged in, create account, and logged in. The first of the three was not logged in. In accordance with the clarity heuristic the most important aspect of this state was its ability to communicate to the user how to move forward which was either logging in or creating an account. To achieve this the conversational tone mentioned earlier was introduced. The assumption based on the familiarity heuristic was to use titles and body text that instructed the user in a more casual tone so the user could be led through their available navigation options more successfully.

Next the create account screen was developed. This page was relatively straightforward in regards to layout. Conversational headings were used to lead the user through the form (familiarity, clarity heuristics). The most important aspect to consider for this page was the information required to create an account. This was kept simple at first and was kept to a username and password. The password field was repeated twice to create purposeful friction so the user could be certain of their password.

Lastly the logged in state was developed. Like the logged out state, the logged in state required a clear direction for the user so once again clear conversation like headings and body text was used to lead the user through the navigation options available to them. In regards to the logged in state the most important of these was access to the Ability profile. 


\section{Expansion}

\section{Ability profile}

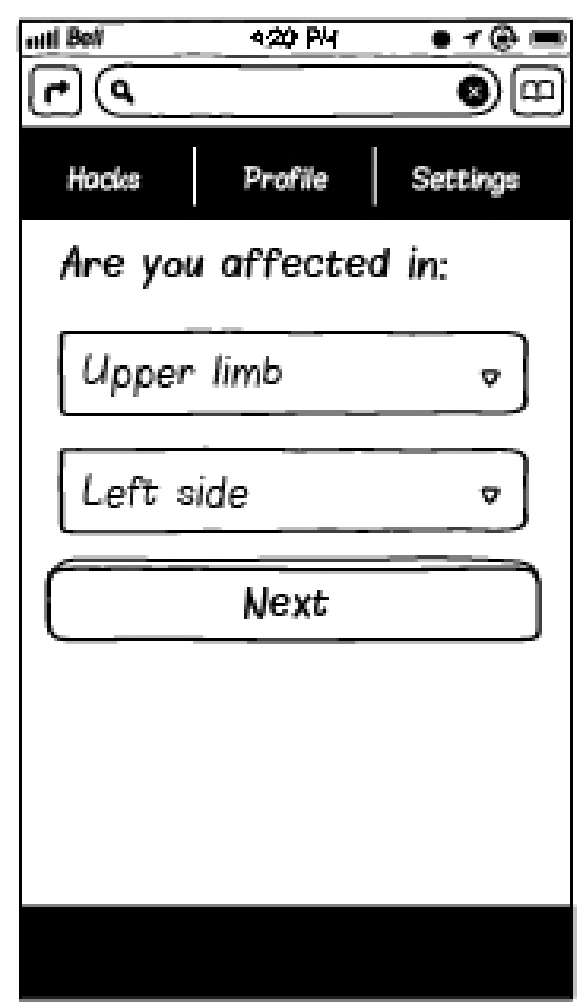

\begin{tabular}{|c|c|c|}
\hline Inill Befl & $420 \mathrm{Pl}$ & 010 \\
\hline \multicolumn{3}{|l|}{$\rightarrow a$} \\
\hline Hacks & Profile & Settings \\
\hline \multicolumn{3}{|c|}{ Are you affected in: } \\
\hline \multicolumn{2}{|c|}{ Upper limb } & $\nabla$ \\
\hline \multicolumn{2}{|c|}{ Left side } & 0 \\
\hline
\end{tabular}

On a scale of not at all to not a problem:

How well can you brush your teeth?

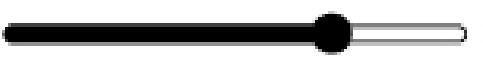

How well can you pull open a door?

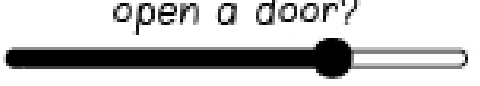

How well can you twist the top off of a bottled drink?

If you answer another 3 questions you'll be able to recieve more refined anwers

Ask away

I'm done 
The purpose of the ability profile was succinctly and accurately summarise a user's physical condition in order to provide a more accurate list of diy assistive technology. In order to achieve this the information gathered from them had to be carefully considered. Initially a more direct route was taken by having a severity and type set of questions asked however an activity based approach was taken in the end. To begin the user would be asked what part of the body was affected by the physical disability (upper, lower, left side, right side). A set of questions based on a list of activities of daily living was generated. The questions were asked in sets of three to meet the simplicity heuristic so the amount of questions would not be overwhelming when showed all at once. This set of questions was dependent on whether or not the user answered upper or lower limb and was asked in sets of three with each set including finer motor skill based tasks. For example beginning with can you push open a door and finishing with can you button a shirt. Each of these questions had a corresponding slider and an ability score was generated from the combined total of the answers: 0 - 30 strong, 30 - 60 moderate, 60 - 90 weak. For instance an object could be filtered based on being for upper limb weakness with a score of 30 . 


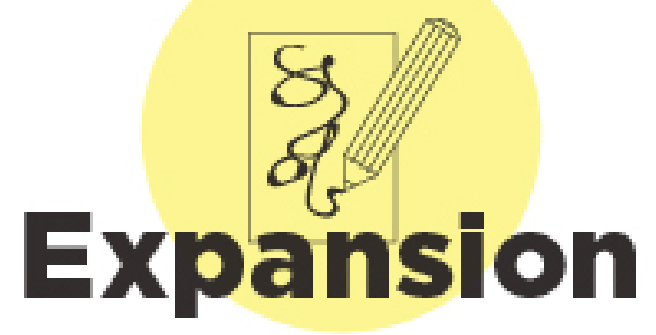

Settings page

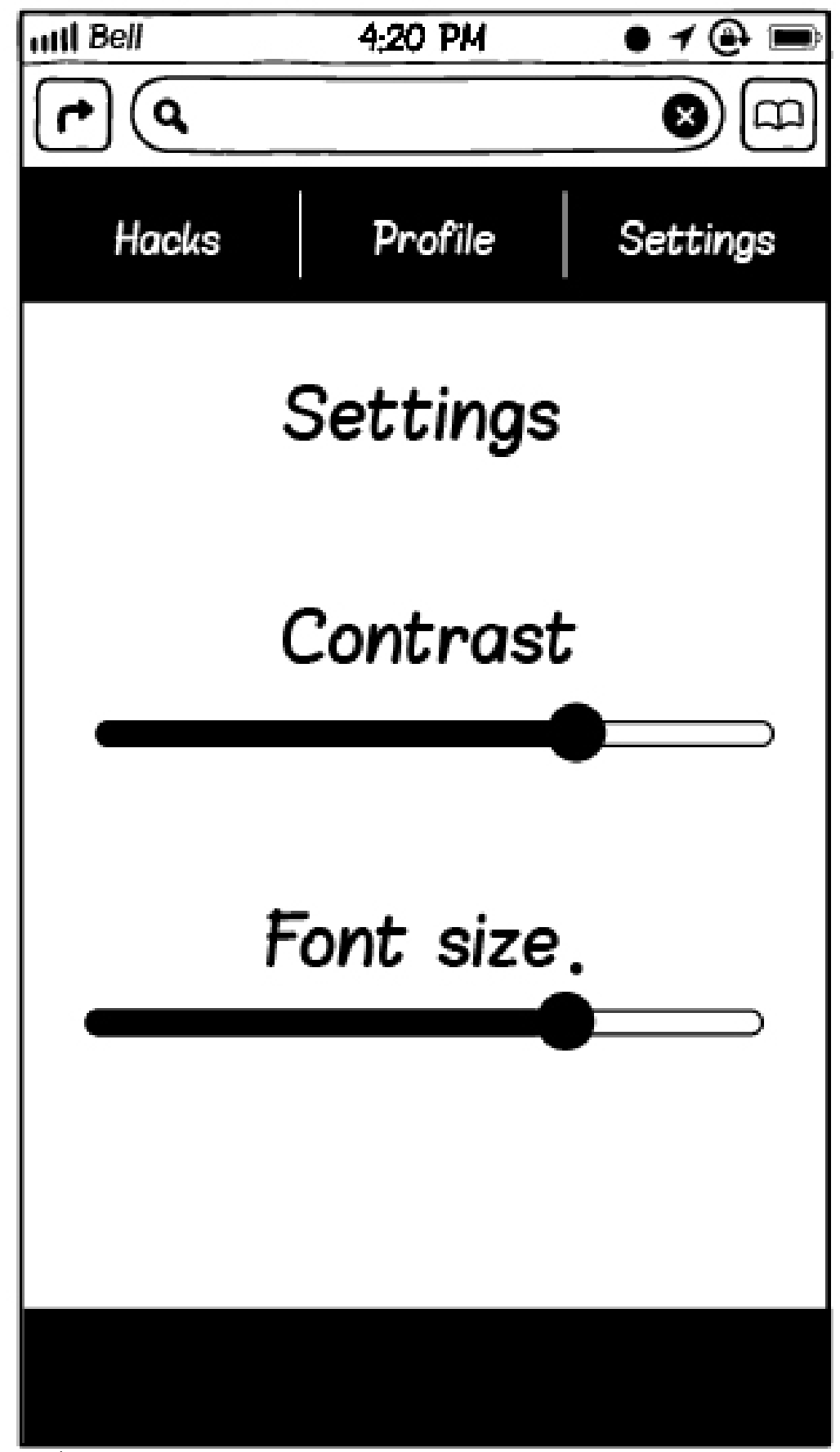

Figure 26: UI concept 
The settings page was relatively simple and had a singular purpose. The sole option included for settings was text size. This came in the form of a slider that dynamically altered the text size across the web application. This was done in accordance with the accessibility and customisation heuristics to compensate for older adults worsened vision. The reason this was given its own page despite it being a singular action was due to the simplicity heuristic so there could only be a single objective per page. There was initially going to be a second slider altering contrast however time constraints forced its exclusion. 


\section{Expansion}

\section{Personal diy page}

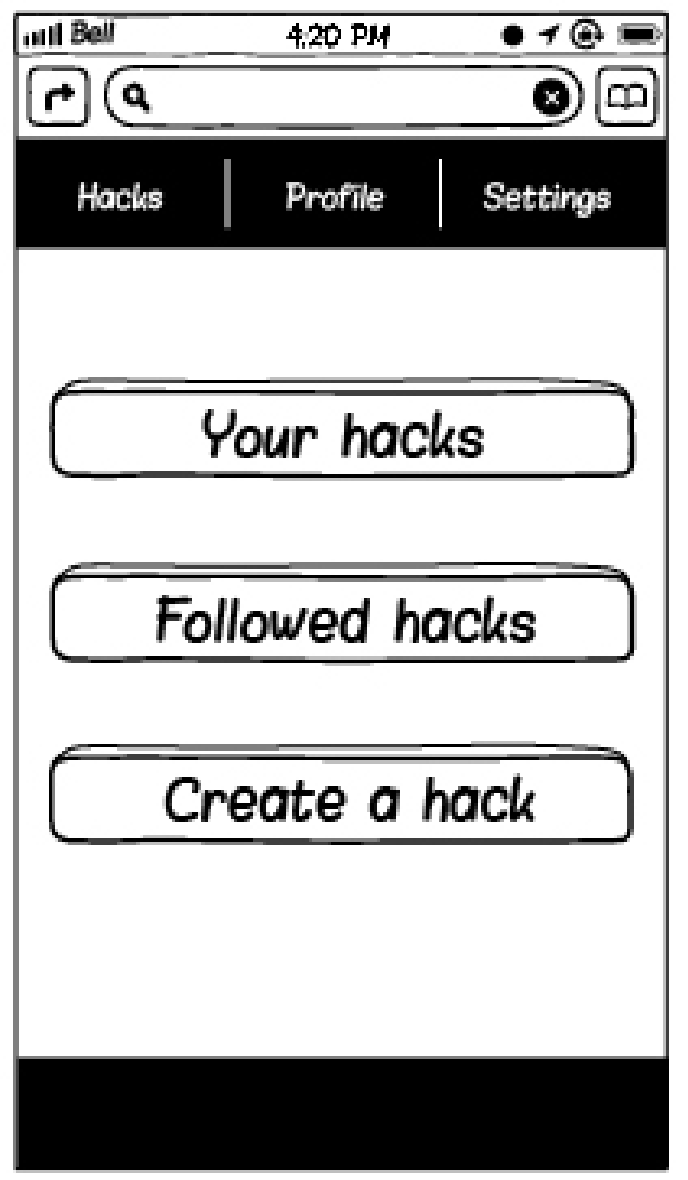

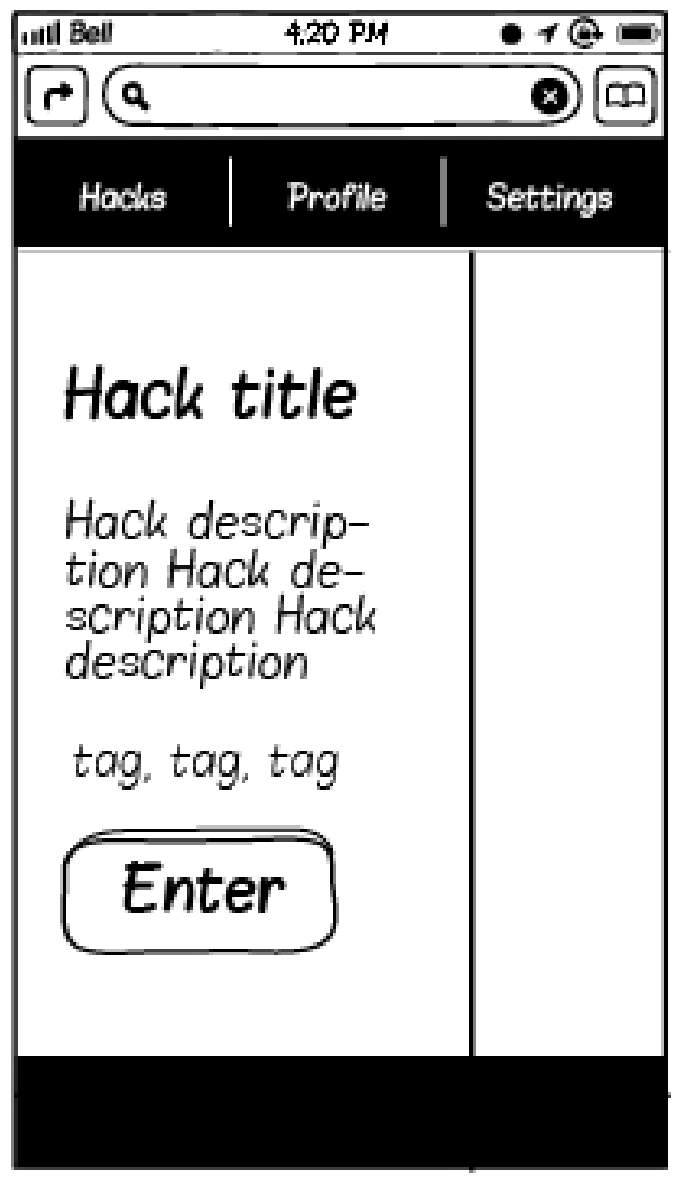


The final page that was added in the expansion was the personal diy page. This page had three base features: display the diy the user had documented themselves, display the diy the user had bookmarked, and link to the create screen. Due to having three features, this page needed to be organised into a two step system to stay compliant with the simplicity heuristic as having all of the information available within this page would've been too confusing. This page begins with three buttons that each are the width of the screen so they can be easy to press because older adults and people post stroke with upper limb weakness can have difficulty accurately pressing buttons (Hanson, 2009)(Becker, 2004); This is also so they can have large text within them to stay in compliance with the accessibility and clarity heuristics. Once a user has selected one of the first two options (user's created diy, user's bookmarked diy) a list of the corresponding diy would appear. To stay in compliance with the consistency heuristic the corresponding diy would appear as though it does on the home screen but with the bookmark button being replaced with a delete button in the user's created diy section and being completely removed in the user's bookmarked diy section. The third option simply leads directly to the create screen. 


\section{Heuristics Review}

Homepage (figure 21)

This page clashed with the clarity, memory, and accessibility heuristics. The biggest issue with this page was with the circular create diy button that appears. It gave no indication as to what it did upon first sight and as a button was inconsistent with every other button within the web application. The enter button also needed to be bigger.

Create account page (figure 24)

This page clashed with the clarity, memory, and control heuristics. This page needed an account create creation title and a cancel button.

Profile page logged in no ability profile (figure 24)

This page clashed with the memory heuristic. This page needed a page title.

Ability profile (figure 25)

This page clashed with the clarity and control heuristics. This page needed a cancel button.

Profile page logged in ability profile (figure 25)

This page clashed with the memory heuristic. This page needed a profile title. It also needed an edit button to stop accidental alteration of the user's profile.

User diy page (figure 27)

This page clashed with the clarity, memory, accessibility, and control heuristics. This page needed titles for your diy and bookmarked diy so they could be told apart. The enter button needed to be bigger.

\section{Settings page (figure 26)}

This page clashed with the familiarity heuristic. Font needed to be changed to text.

Profile page not logged in (figure 24)

This page clashed with the clarity, familiarity, and consistency heuristics. This page was reasonably clear however the start browsing element needed work 
to be clearer and there were a lot of options in regards to navigation right off of the bat. There was also no introduction of any sort which may leave the user a bit lost.

Documentation page (figure 23)

This page clashed with the clarity and accessibility heuristics. This page had a few small issues: the close button needed to be bigger and clearer and follow needed to be renamed also the dead space at the top needed to be corrected.

Diy creation page (figure 22)

This page clashed with the clarity, memory, and accessibility heuristics. This page needed titles to be clearer so the user knew what part of the creation process they were in. It also needed a cancel and done button at the top and a message about the purpose of the page so there was no confusion. 


\section{Finalised UI}

This section details changes made to each page based off of the heuristic analysis.

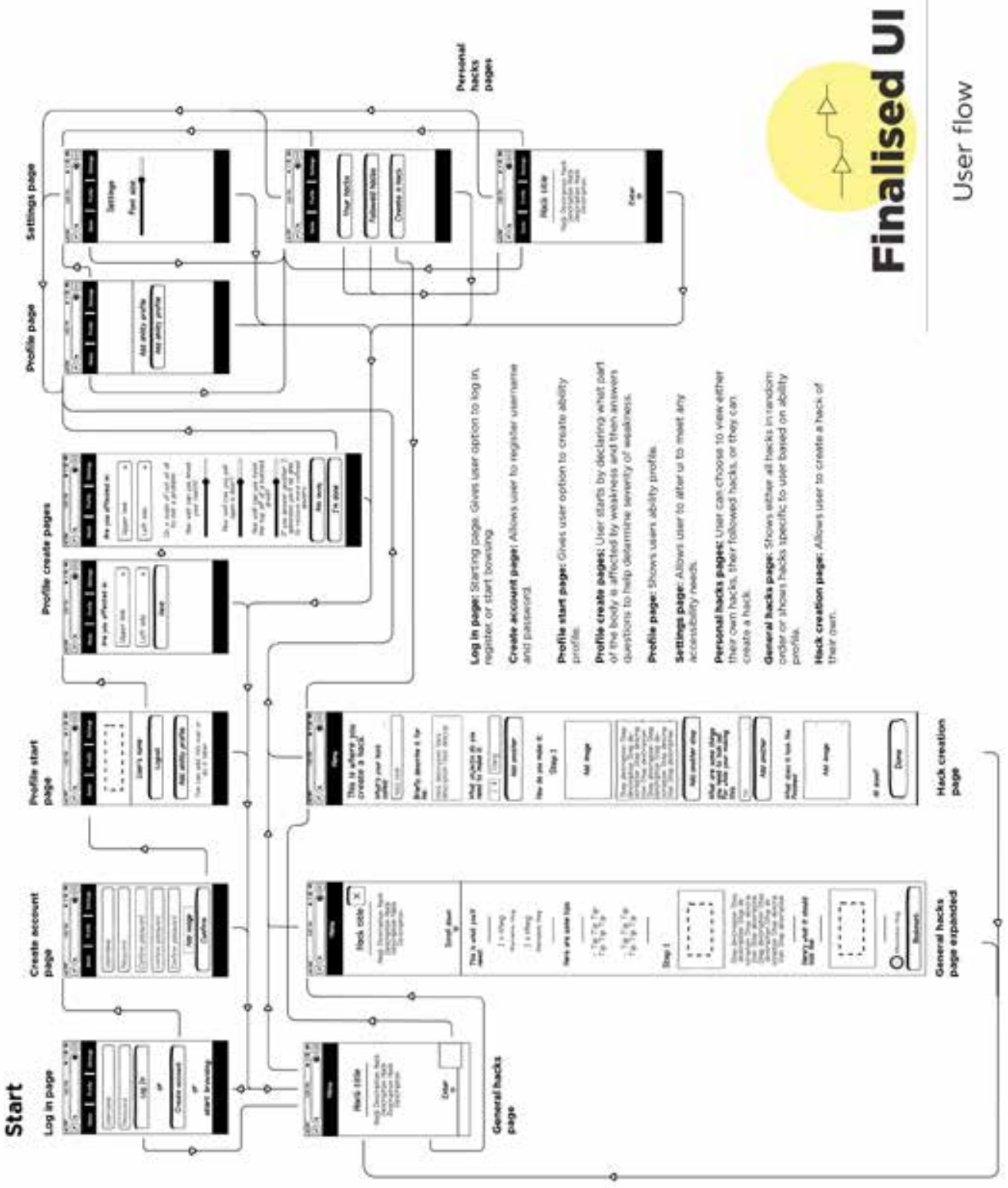

Figures 28-29: User flow diagrams 


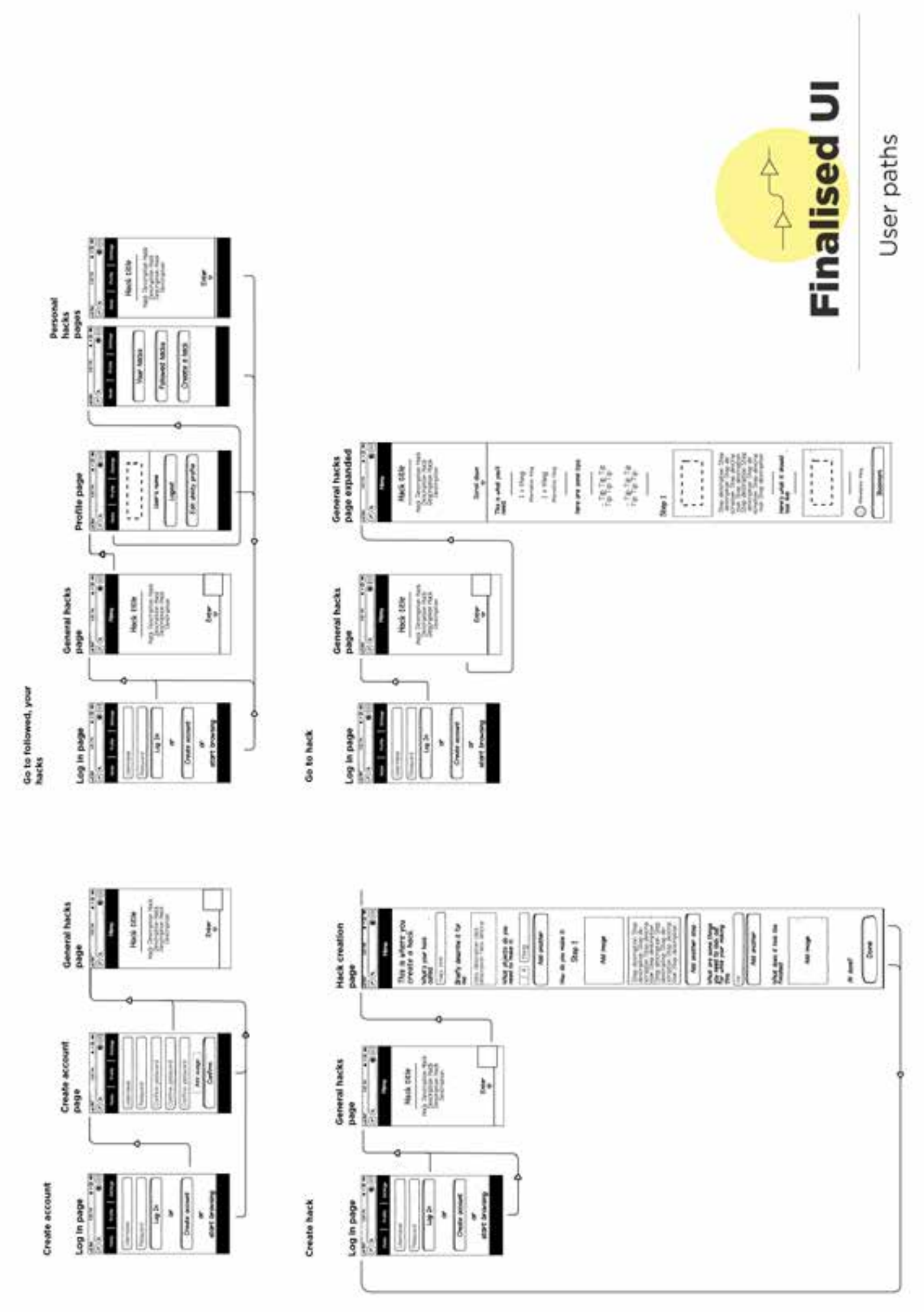




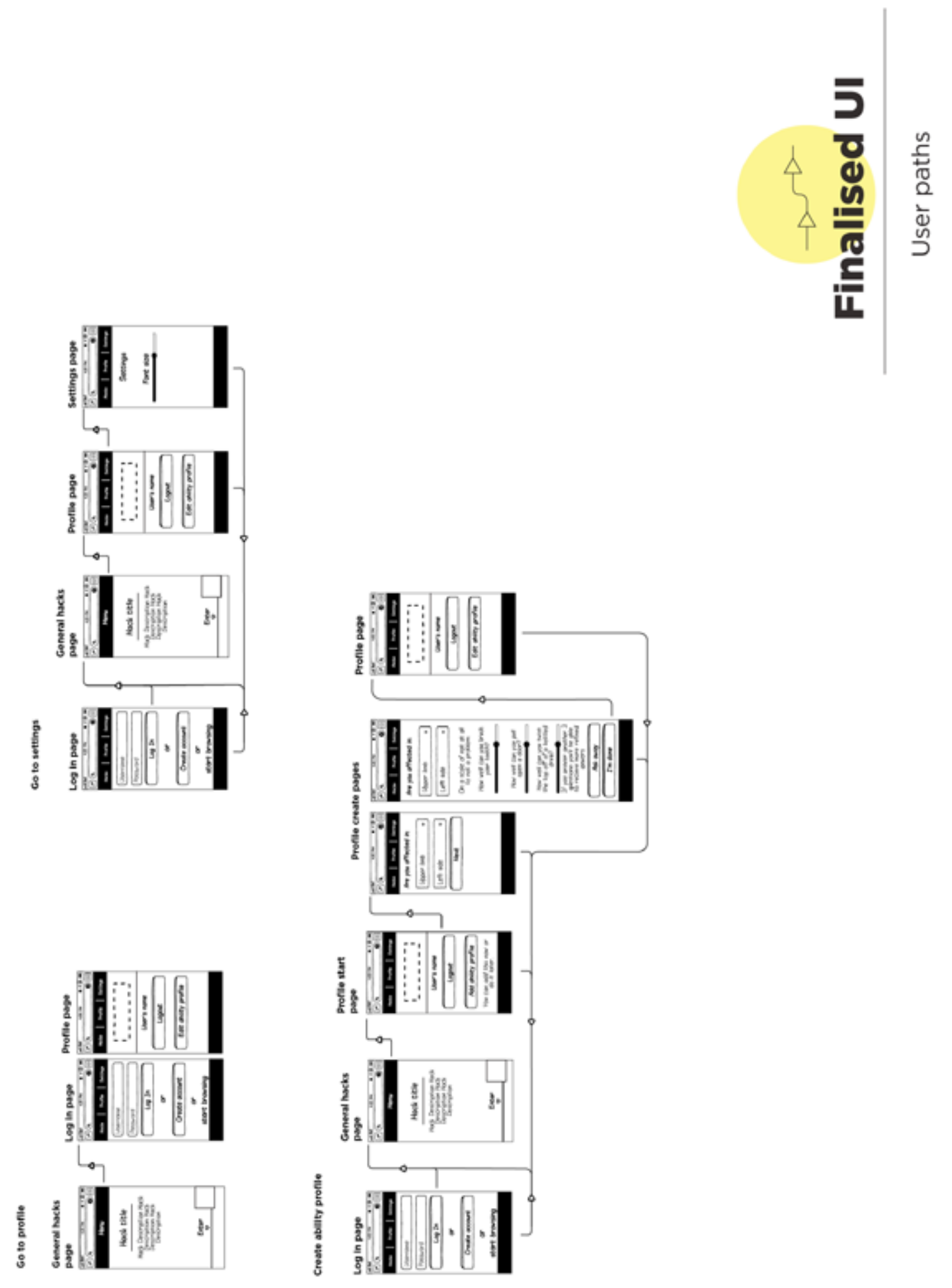

Figure 30: User flow diagrams 
Home page (figure 28)

The homepage was changed from diy creation list page to the profile page. This was because there is more space available to introduce the users to the application for the sake of onboarding rather than having a clunky pop up appear. Due to this introductory text was included at the top of the page. The start browsing text was moved onto the navigation bar at the bottom also.

Create account (figure 28)

Create account had changes with the information that was requested of the user. First name, last name and photo were included so that the profile page could be more accommodating once the user logs in. Also a title and cancel buttons were added.

Ability profile (figure 28)

Despite being included in the user flow and functional this page was removed in preparation for testing. The reason for this is due to the limited amount of diy creations displayed on the application the effectiveness of this feature couldn't be accurately tested and so was removed to simplify the profile page.

Profile page logged in (figure 28)

This page had the ability profile button removed due to reasons stated previously. It also had the profile picture change to be larger and more visible and have the user's name displayed at the top to indicate it being a profile.

User diy page (figure 28)

This page had the size of the buttons altered to be bigger. Titles were not included however as there was no space to do so.

Settings page (figure 28)

This page had font changed to text and the contrast option removed.

Diy creation list page (figure 28)

This page was simplified greatly. The text was centered and the tags were removed. The solid block the text covered was also removed. The button to enter the diy creation was changed to text at the bottom however the hit box was the width of the screen and two thirds the height. This clashes with the consistency heuristic in regards to button consistency however felt like the right option. The button that links to the create page was changed to a 
square with the text create across it.

Documentation page (figure 28)

This page was changed a fair amount. The largest change was to the information presented within it. The materials section now included an alternative option so the user would be given an idea of the type of object they need rather than being given a specific selection. The second description was removed as it was excessive. A tips section was included to give the user small bits of information they may not have considered during the building process. These changes were included to make the documentation more process oriented. The how to use portion of the instructions was removed due to clashes with the flexibility heuristic. The final change to the information was the inclusion of a finished image at the end. The information was also more spaced out to make it more readable.

Create page (figure 28)

This page had the same information changes as the documentation pages. The biggest change came in the way the information was presented. In order to match the creation process of a user the tips were included after the steps section and the finished image form option was included at the end. A close button was included at the top of the screen and the information was spaced out. 


\section{Aesthetics}

\section{Typography \& colour}

Hack title Hack title

Hack title Hack title

Hack title Hack title

Hack tltle Hack title

Hack title Hack title

Hack title Hack title

Hack title Hack title

Hack title Hack title

Hack title Hack title
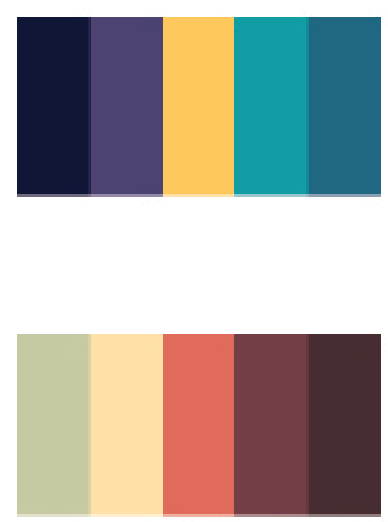

Roboto Slab

Monserrat

Merriweather Merriweather

Monserrat

Gotham

Roboto Slab

Roboto

Roboto Slab

Open Sans

Merriweather
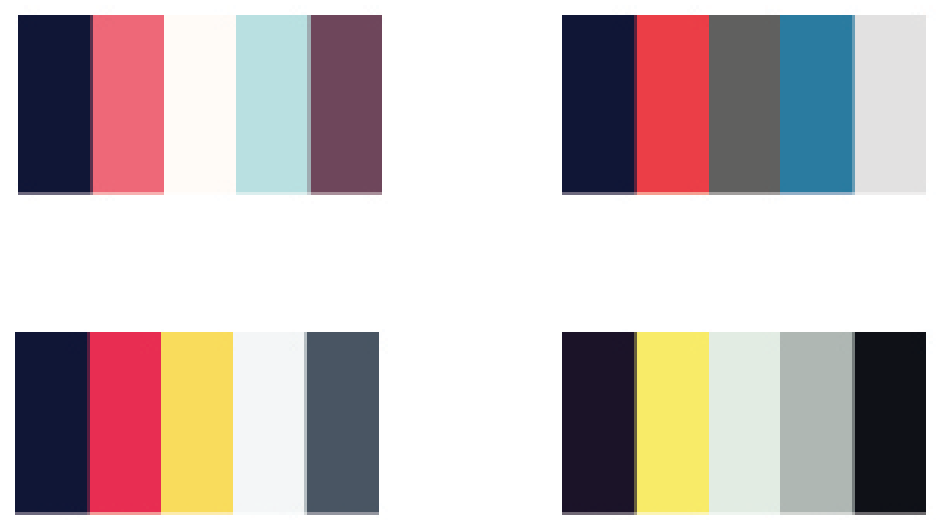
The final requirement for designing the user interface was developing aesthetics. To successfully achieve this instead of designing each page individually one page were chosen to develop aesthetic rules to then translate to each page in accordance with the consistency heuristic. The page chosen was the diy creation list page.

The first aesthetic consideration made was the selection of typefaces. As seen in figure 31 nine typefaces were trialled: Bitter, Avenir, Roboto, Gotham, Lato, Merriweather, Montserrat, Roboto Slab, and Open Sans. Of these Roboto Slab, Roboto, Montserrat, Gotham, Merriweather, and Open Sans were trialled together to identify aesthetically pleasing pairings that also had identifiable differences in how they look. This was required because in order to conform to the clarity and consistency heuristics the typeface used on interactive screen elements needed to be different than the typeface used on body text. The typefaces that were chosen were Open Sans and Merriweather. Open Sans was used for body text because as a sans serif it is very legible and has multiple fonts so can be used for headings, paragraphs etc. Merriweather was used for interactive elements because it was identifiably different from Open Sans while still being legible.

As seen in figure 31 the next consideration that needed to be made was colour pallette. In order to successfully choose colours a few considerations needed to be made in relation to the consistency, accessibility, and familiarity heuristics. The first consideration was the perceptual difficulties faced by older adults. Due to degrading vision the colours chosen had to have high contrast to compensate for this lowered visual acuity and also no patterned backgrounds could be used due to this same reason. (Hanson, 2009)(Becker, 2004). Another was the yellowing and thickening of the lense that occurs in the eyes of older adults affecting colour perception. Lastly due to older adults sometimes struggling to discern between visual elements (Chadwick-Dias, McNulty, Tullis, 2004) these colours needed to make the difference between interactive and non-interactive elements very clear. 
Figures 32 - 33 show the final user interface ready for user testing:

\section{Aesthetics}

Final
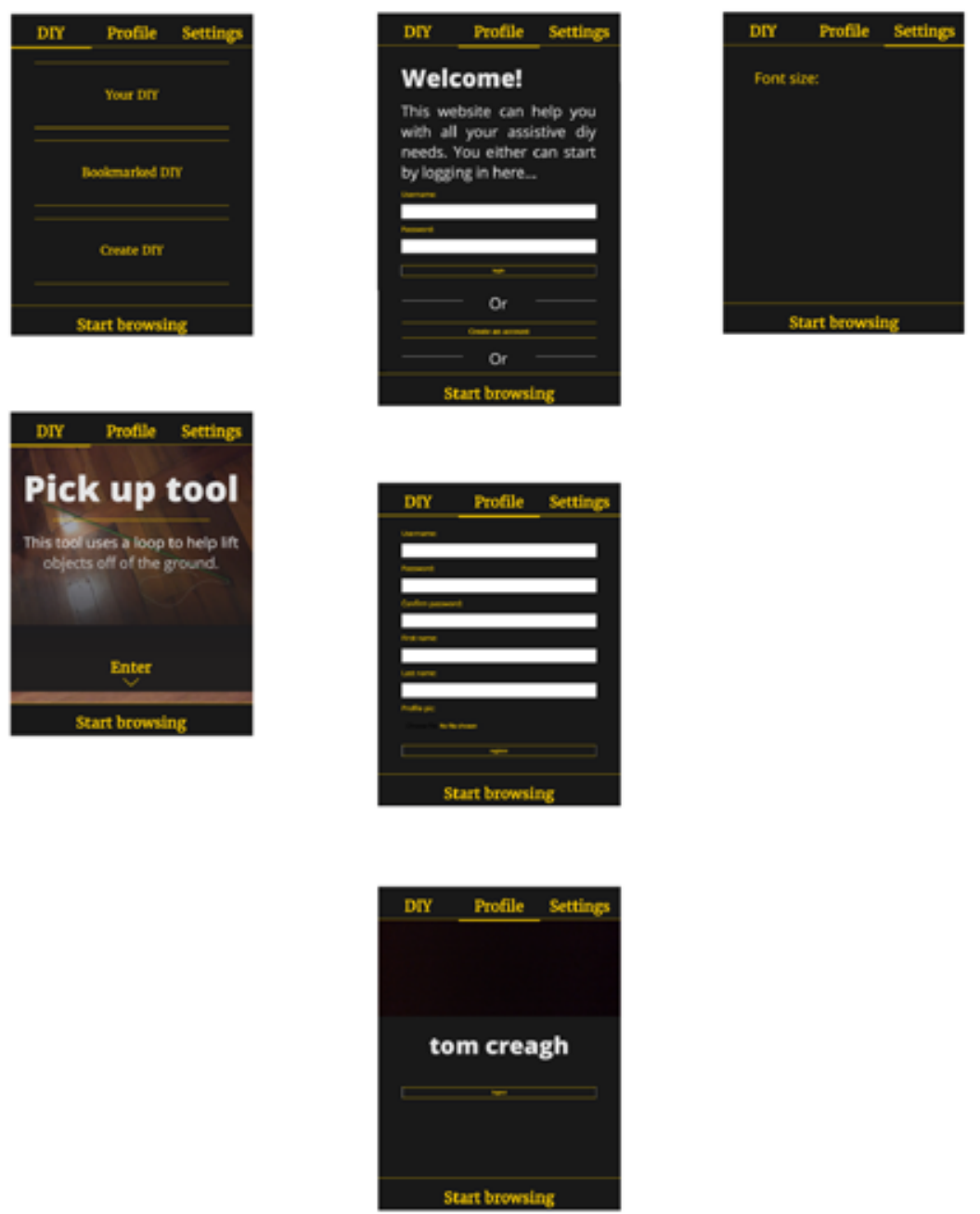

Figure 32-33: Finalised aesthetics 

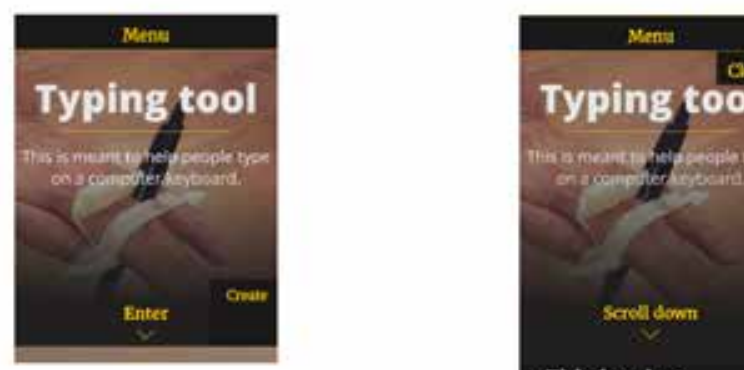

This is what

you'll need:

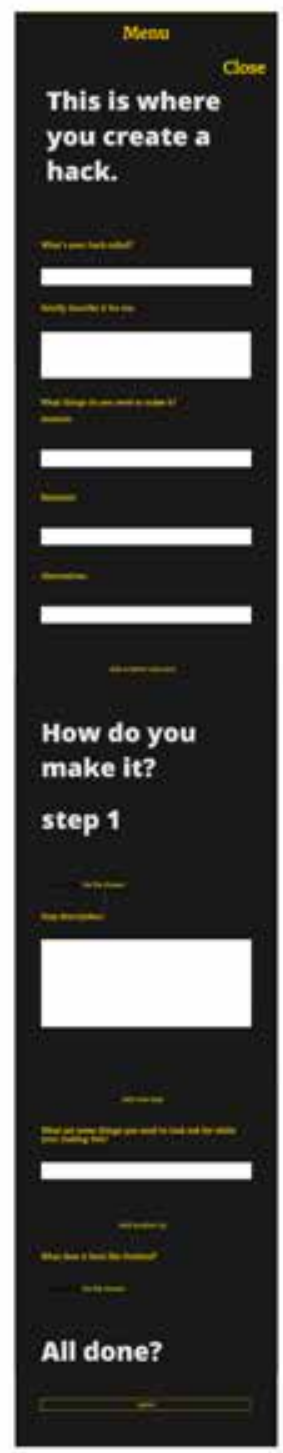

4 Plustic stript

구을

$1 \times$ pen whth dip

드.

7 X Ras cat upe

드.

Here are

some tips:

Mate wre sepen has a

merible cin wor wa not mep

cinier to mate if voucos

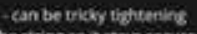

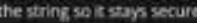

step 1

(O)

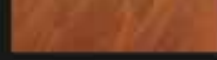

Sart by taing the tour

Here's what

it should

look IIke:

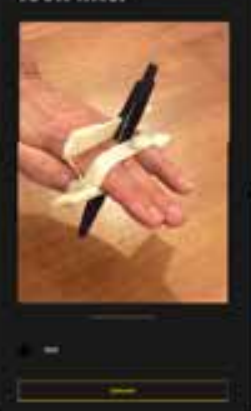


Diy assistive technology 


\section{Diy assistive technology examples}

The following section details the development of the three pieces of diy assistive technology created for use in the web application. The purpose of these being to provide users an object to create during the user testing phase.

\section{Pick up tool:}

The pick up tool is designed to help people pick objects off of the ground. It requires a pipe, line trimmer wire, and string to make. To use it a person must place the loop at the end over an object they wish to lift and pull on the string at the opposite end so the loop tightens around the object. While holding the string, the person using the tool can then lift the object to where they want it.

The idea originated from the traditional claw based pick up tool. The mechanism for a claw based pick up tool is too complicated for a simple diy conversion and the materials required for the claw would need to be too specific (something strong enough to grip and not break) so an alternative direction needed to be taken. To simplify the tool the core requirements of it's functionality were established: the ability to tighten around or grip onto an object, the ability to maintain that grip or tightness, and the ability to tighten around or grip onto an object from a distance.

The solution came in the form of a noose. A noose is relatively simple to tie and is versatile in its applications. The use of a noose met the first two functionality requirements. To meet the third requirement a pipe was used to thread the noose through. The initial prototype used guitar string for the noose, twine, and a thin aluminium pipe. The materials were changed for the final iteration. A stronger pipe was used because during testing of the initial prototype the thinner pipe bent when heavier objects were lifted. The guitar string was changed to line trimmer wire and the twine was changed to string because each material is easier to procure. 

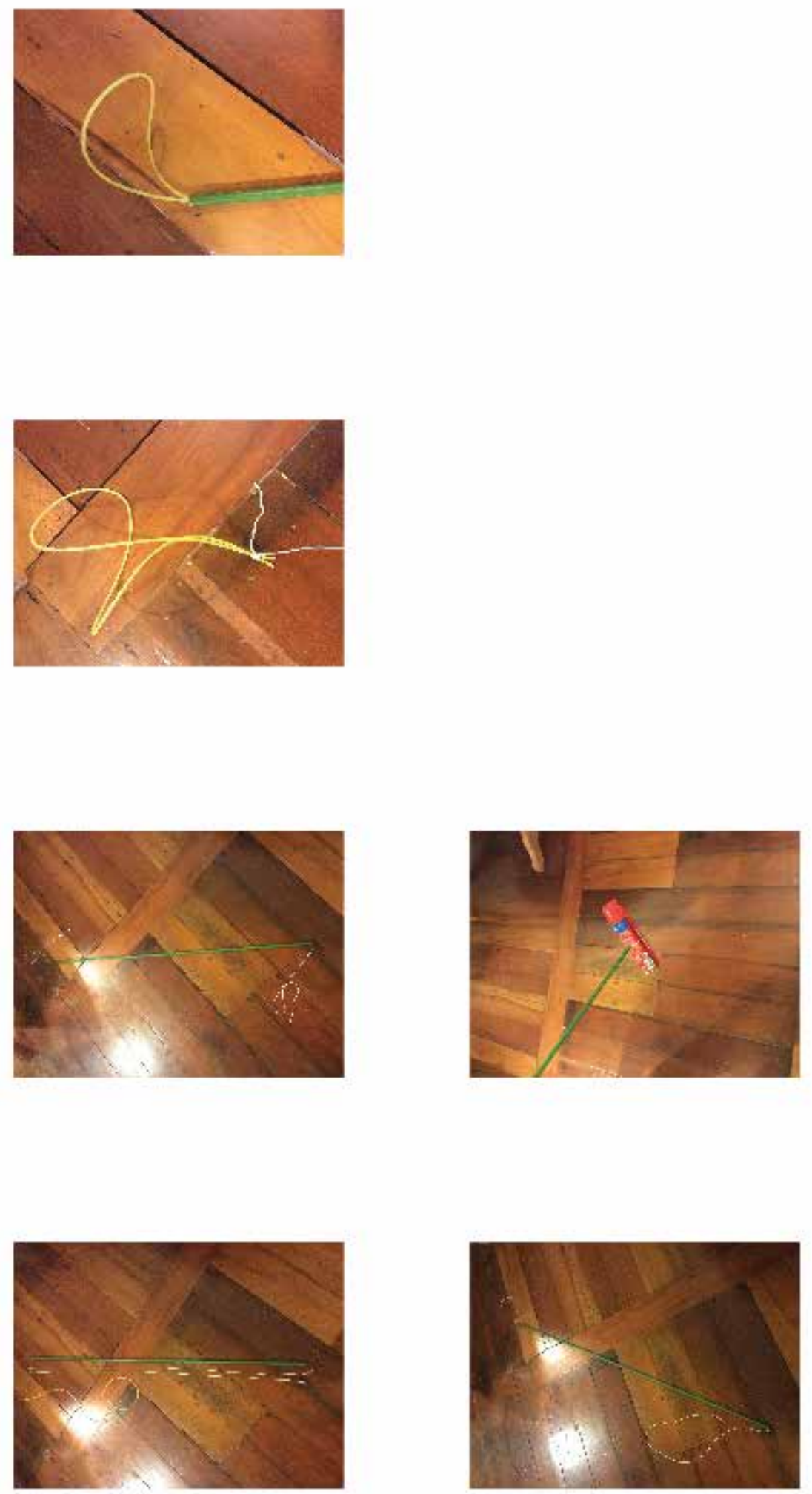

Figure 34: Diy assistive technology building process 


\section{Typing tool:}

The typing tool is designed to help people with hand weakness type on a computer keyboard. It requires a pen, plastic strips around $100 \mathrm{~mm}$ in width, and tape to make. To use it a person must insert their hand into the plastic strip with the pen attached to it just below the knuckle with the tip of the pen going between the middle and ring fingers. Then they must slide the plastic strip with the tighter loop as far up their fingers as they can so that it is tight and secure. They can then use then use the pen to type.

This tool was based off of another commercial typing tool. The concept behind this product is simple and can be translated well into a diy alternative. The core requirements of this tool's functionality were established as: The ability to apply downward pressure, the ability to apply that pressure with minimal movement and/or strength and/or dexterity in the hand, the ability to hold that pressure for as long as required.

The solution was to use a pen clipped to a handle of some sort. The pen was decided upon due its ease of procurement and it emulated the commercial product quite suitably. The handle that the pen was attached to initially used popsicle sticks and tape. The tape was wrapped around the popsicle stick to create a handle so it could slide onto the hand. This would allow the tool to meet the first and second requirements however during testing it was established that a single handle wouldn't stay on the hand due to it being too loose or allow for much pressure to be applied due to nothing holding the pen in place. Due to this a second handle was added. The second handle was tighter and slid over the top of the pen to allow for pressure to be applied. For the final iteration popsicle sticks were changed to plastic strips because standard popsicle sticks are too wide for the hand. 

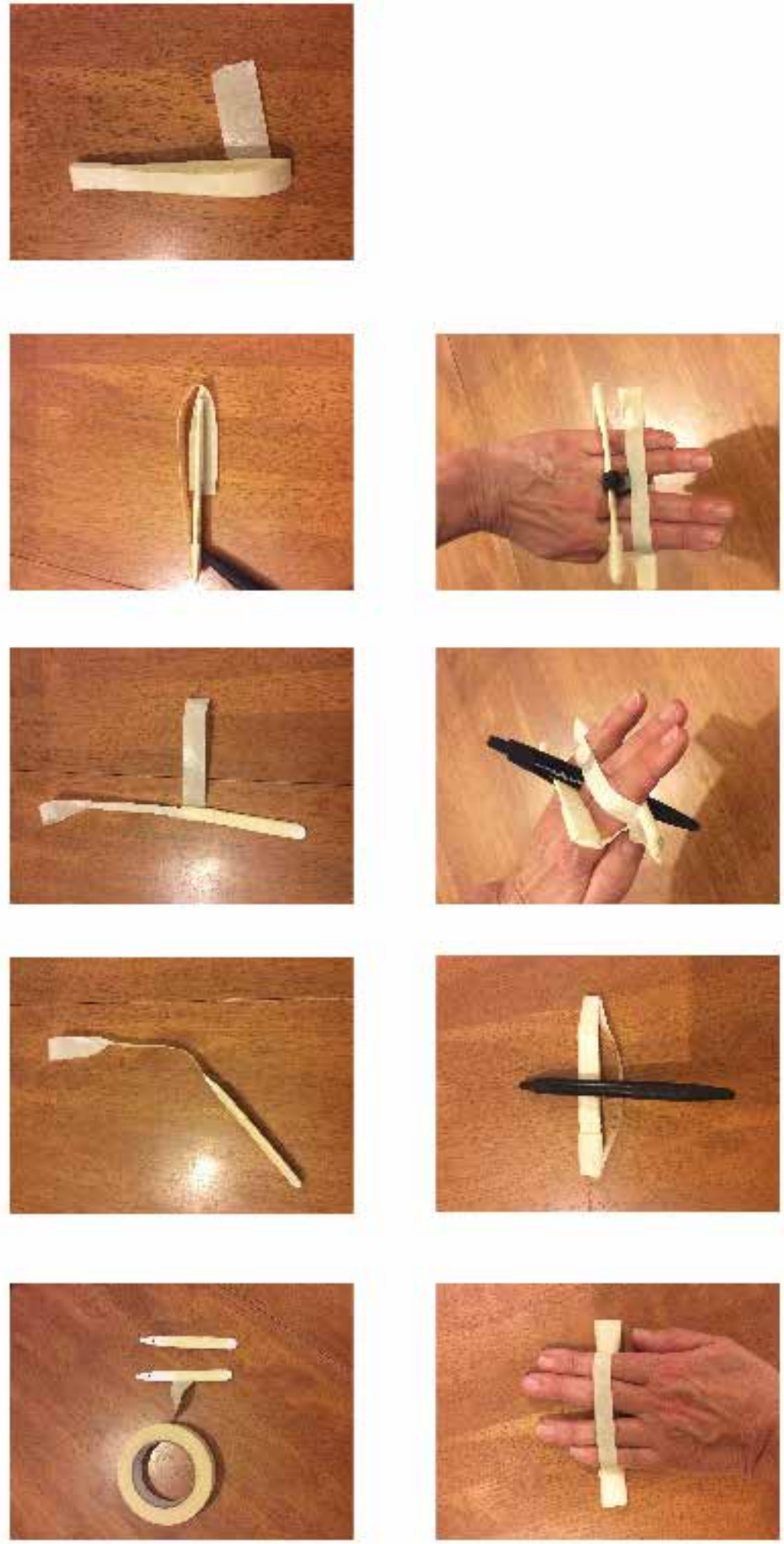

Figure 35: Diy assistive technology building process 


\section{Utensil holder:}

The utensil holder is designed to help people with grip weakness to hold utensils like forks and spoons. It requires a sheet of plastic, string, and scissors to make. To use it a person must slide their hand into the strings with the loop side facing up and under their index finger. The string coming out of the hole next to the loop needs to go between their index and middle fingers. Next they must pull the dangling string underneath to tighten it over your hand. Then they must secure it by taking that end of the string and pulling it through the middle hole. Then they can insert a utensil of some sort through the noose style loop and tighten it.

The utensil holder tool was based off of generic commercial assistive utensil holders. This tool was chosen because due to its simplicity it would translate well into a diy tool. The core requirements of this tool's functionality were established as: The ability to keep an eating utensil secured to a hand with little to no grip strength, and the ability to keep an eating utensil secure for extended periods of time.

The solution matched the generic commercial products fairly closely due to their simplicity. The initial prototype used twine and cardboard. Developing the base for the utensil to rest on was relatively simple and just required the cardboard to be cut to an appropriate size for the hand. Securing the base to the hand and the utensil to the base was more difficult however. The solution to securing the utensil was to use a noose style knot positioned at the top of the base, next to the thumb. A noose allowed for an easy, reusable method of both tightening and loosening. This allowed for a solution to securing the base to the hand also. By threading the twine with the noose through intentionally placed holes across the base, loops could be made to place the hand through. The final iteration used plastic instead of cardboard so it would be more durable and string instead of twine because it was less irritating to the skin. 

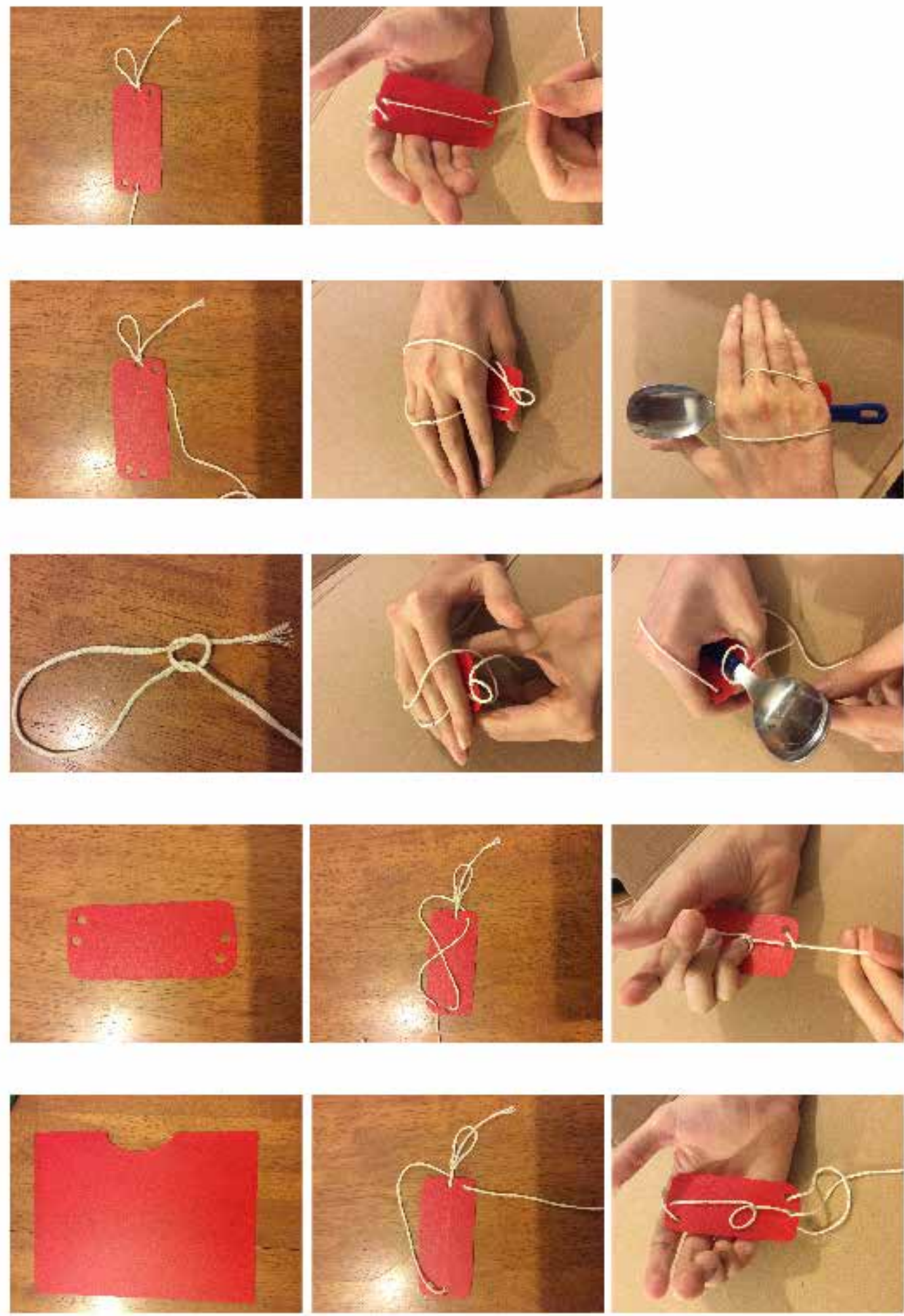

Figure 36: Diy assistive technology building process 


\section{User Testing}




\section{User Testing}

The following section details the user testing process that was undertaken to establish the web applications usability and the efficacy of the instructions provided.

\section{Participants}

Criteria to participate in this study was as follows:

- Over 18 years of age

- Have a physical disability as a result of stroke

- Have had no physical or cognitive disabilities prior to the stroke

- Have no cognitive disabilities as a result of stroke.

Participants were recruited through Lower Hutt stroke club. 25 - 30 potential participants were spoken to and of those people three agreed to participate, however one was disqualified due to aphasia. Both participants were over the age of 60 and neither had any disabilities prior to having a stroke.

Participant A was a male who has left side hemiplegia as a result of stroke. He had his stroke in 2006 and uses a cane to walk.

Participant B was a female who has left side hemiparesis of the lower limb as a result of stroke. She had her stroke in 2014 and uses a cane to walk.

\section{Testing procedure}

One testing session was undertaken with each participant. These two sessions were done individually and were split into three parts. Each session took roughly one hour. The testing sessions took place at Petone library where a meeting room was hired and used.

The first part featured an interview with the participant. This interview took roughly ten minutes and centered around two topics: assistive technology use and internet use. The assistive technology portion of the interview was used to assess what assistive technology the participants had used, what their experience was with that assistive technology, and if they had engaged with diy in any way in regards to assistive technology. The internet usage 
portion of the interview was used to assess prior use of the internet and what devices they had used to access the internet.

The second part of the testing process featured the user testing session. This part of the process took roughly forty minutes had two core parts: testing the usability of the web application and testing the diy documentation.

The web application usability portion of the user testing was undertaken on an ipad. This portion of the user test required the participant to complete four tasks that reflect typical end-user goals when using this web application. The four tasks were create an account, logout and login, change the text size, and find and bookmark a diy creation of their choice and locate that bookmarked creation in the bookmarks section. The participants were assessed based on completion time, how many of the tasks they could complete. The tasks were provided to the user on a paper document () and if they felt they could not complete a task a box for them to state why was provided.

The second part of the usability test was testing the documentation. Users were asked to select the diy creation they had bookmarked and follow the instructions and create the corresponding object to the best of their ability. All materials they would require were provided for them. Users were assessed based on completion time and accuracy of results.

The third and final portion of the testing was a questionnaire(). This questionnaire took roughly five minutes. The questionnaire was based on the SUS (system usability scale) (Sauro, 2011) which is a set of ten usability questions that uses the level of agreement version of the likert scale (Vagias, 2006) (a 5 point scale that begins with strongly disagree and transitions to strongly agree) to determine an answer to each question. A result was gathered from this questionnaire by adding all responses (to a total from 0-40) and multiplying the result by 2.5 so the scale was $0-100$. The final score giving a quantitative indication of usability. There were three questions asked about usability positioned at the end also. 


\section{Testing results}

\section{Interviews}

\section{Participant A}

The first portion of the interview was based around assistive technology use. Participant A said that they had used assistive technology in the past. He used a walking stick and a cast which kept his hand straightened out. He believed both had been of help to him. Although he found assistive technology helpful and had no ill feeling towards using it he prefered to do things without any assistance whenever possible as he wanted to maintain his independence. He received personal care however said he said he sometimes ignore given advice. He also had not attempted to seek out any assistive technology saying he believed the hospital system had pushed him away. He had also not attempted to create any sort of diy assistive technology however said he would be interested.

In regards to internet usage, participant $A$ said he had never used the internet before. He said he was hesitant to try because he had very little knowledge about it. He had never used a mobile device either.

\section{Participant B}

Participant B had used assistive technology. She used a walking stick for mobility but that was the only thing. She said that she could not go without it when she was out in public, however, at home she could hold onto furniture. She said she accepts her need for assistive technology but wishes she did not need it. She received physical assistance from her husband. She had not seeked out any assistive technology saying she had not found a need to in the past as she tries to remain as independent as possible. She had not attempted to create any sort of diy assistive technology either stating the same reasons.

In regards to internet usage participant B said she had not used the internet since her stroke because she felt it was just another thing to worry about and didn't need that in her life although she did have an email address but got 
her husband to operate it for her. She did have minimal use in the past which consisted solely of visiting news sites. She also expressed interest in taking a class to learn because she had been given an iPad. The iPad was her preference over using a computer.

\section{User testing session and questionnaires}

\section{Participant A test}

Figures 37-40: User testing with participant A
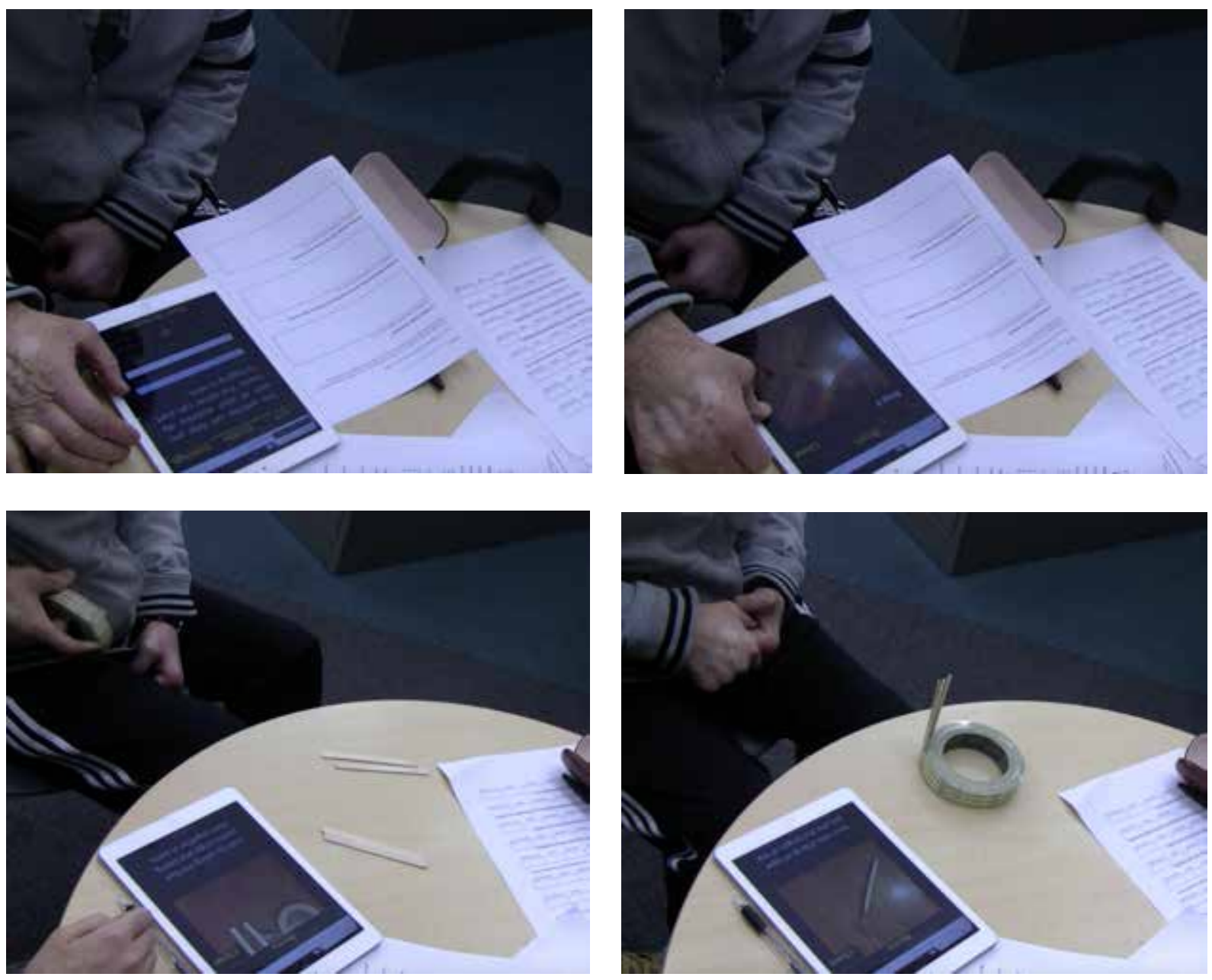

Participant A had never used the internet or any sort of mobile device before so to begin he had to be taught how to scroll and click on the iPad. Although he understood he needed to follow the instructions presented to him he did not understand basic internet jargon like accounts. This was consistent with findings from Chadwick-Dias, McNulty \& Tullis (2004) that 
common jargon may not be understood so was anticipated to some degree and an attempt was made to correct it through using identical language on the task sheet and application but proved ineffectual as participant a was unable to complete any tasks asked of him in the portion of the user test with the web application. He stated in the task sheet that this was because did not understand how to use the web application across each task box.

For the second part of the user test, participant A selected the typing tool as the diy creation he wished to make. Due to him not being able to complete any of the tasks and his inexperience with the internet he had to be assisted in selecting one of the three diy creations available. He also had to be partially assisted scrolling through the instructions as he attempted them. He initially started by scrolling back and forth through the application until he eventually selected popsicle sticks, tape and a pen from the materials provided. He then moved to the tips list and made certain the pen he had was suitable. He then scrolled to the first step and after attempting it he decided stop as he wished to go home to see his son.

\section{Observations}

At the very beginning of the testing period it was clear that due having no experience with the internet or handheld devices the user would struggle. The lack of experience made the user seem uncomfortable and reluctant to try clicking things this was established by Chadwick-Dias, McNulty \& Tullis (2004) so was expected however the extent to which it occurred was unexpected as it was assumed the user would have some experience let alone expertise. Basic interactions like scrolling and clicking were performed incorrectly despite attempting to teach the user how to do so. Other assumptions made about operating the device were proved wrong very quickly when viewing the user navigate the application. Another being that including conversational headings would assist in helping identify options available to the user. It seems as though using a long introduction actually impeded their ability to move forward as it forced elements to be hidden below the fold (the portion of the screen visible to the user before scrolling is required) while they scroll. It is unclear if this is directly due to the inexperience of the user or the length of the paragraph however. Although the user did scroll a small amount on the home screen they did not scroll to the create account button and after selecting the start browsing button did not return to this screen. Another assumption that proved wrong was 
that showing a small portion of the diy creation below the one currently on screen would encourage scrolling. One thing that may of caused this was making the button to open a hack so large. While it was done to match the accessibility heuristic it did break the consistency heuristic and was a mistake.

\section{Questionnaire results}

Figures 41: Questionnaire answers given by participant A

\begin{tabular}{|c|c|c|c|c|c|}
\hline & $\begin{array}{l}\text { Strongly dis- } \\
\text { agree }\end{array}$ & & & & $\begin{array}{l}\text { Strongly } \\
\text { Agree }\end{array}$ \\
\hline & 1 & 2 & 3 & 4 & 5 \\
\hline $\begin{array}{l}\text { I think that } \\
\text { I would like } \\
\text { to use this } \\
\text { system } \\
\text { frequently }\end{array}$ & & & & & \\
\hline $\begin{array}{l}\text { I found the } \\
\text { system un- } \\
\text { necessarily } \\
\text { complex. }\end{array}$ & & & & & \\
\hline $\begin{array}{l}\text { I thought } \\
\text { the system } \\
\text { was easy to } \\
\text { use. }\end{array}$ & & & & & \\
\hline $\begin{array}{l}\text { I think that I } \\
\text { would need } \\
\text { the support } \\
\text { of a techni- } \\
\text { cal person } \\
\text { to be able } \\
\text { to use this } \\
\text { system. }\end{array}$ & & & & & \\
\hline $\begin{array}{l}\text { I found the } \\
\text { various } \\
\text { functions in } \\
\text { this system } \\
\text { were well } \\
\text { integrated. }\end{array}$ & & & & & \\
\hline $\begin{array}{l}\text { I thought } \\
\text { there was } \\
\text { too much } \\
\text { inconsis- } \\
\text { tency in this } \\
\text { system. }\end{array}$ & & & & & \\
\hline
\end{tabular}




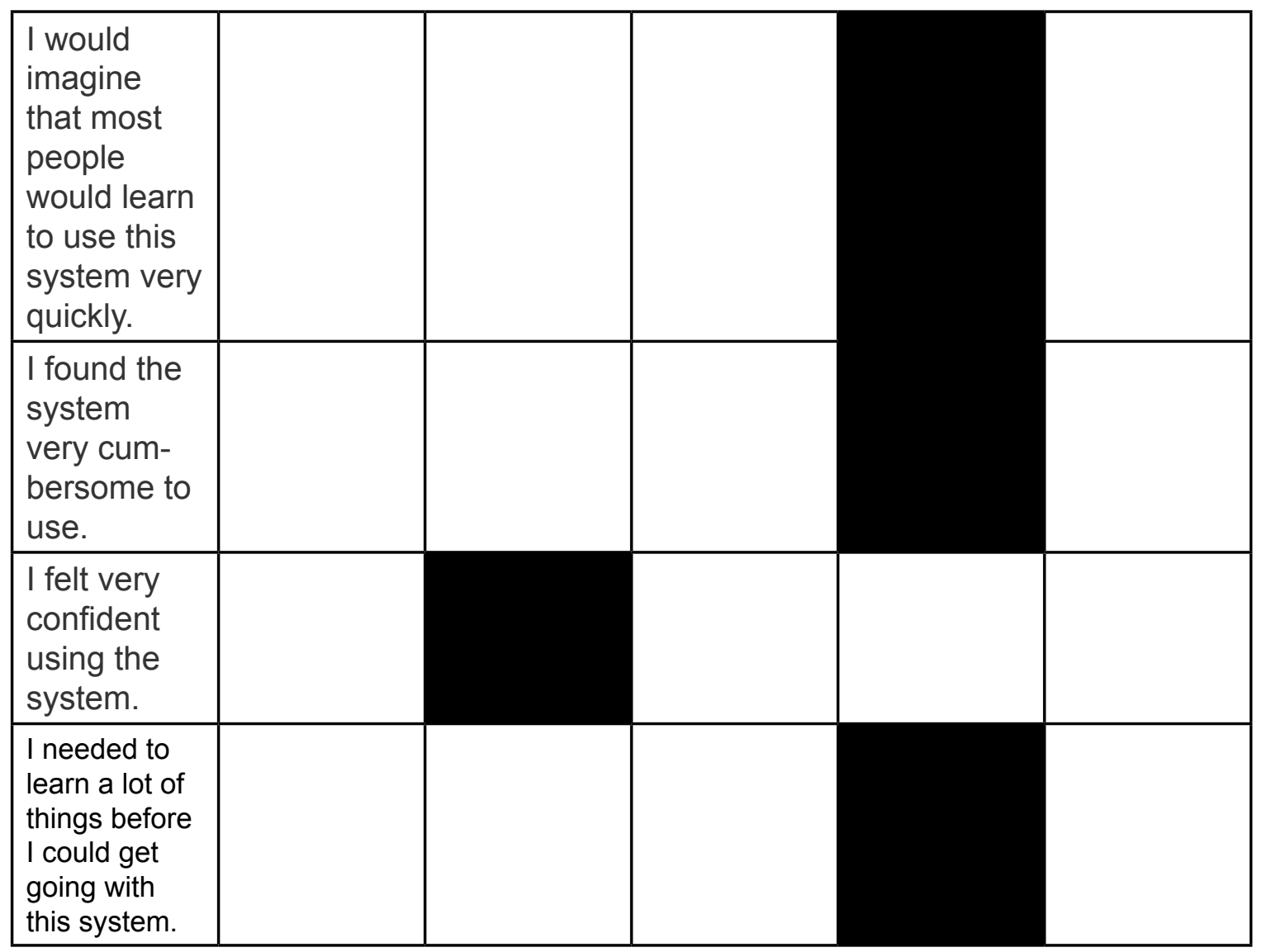

The SUS score for participant A was 40 . This is a relatively low score for for the SUS. This would indicate that for an inexperienced user this web application is very difficult to use.

For the questions at the end of the questionnaire participant $A$ gave the answers:

- Question 1: Easy.

- Question 2: No.

- Question 3: Yes.

These three answers were short and did not reflect the observed attempt at following the instructions so, while favourable, do not seem entirely valid. 


\section{Participant B test}

Figures 42-45: User testing with participant B
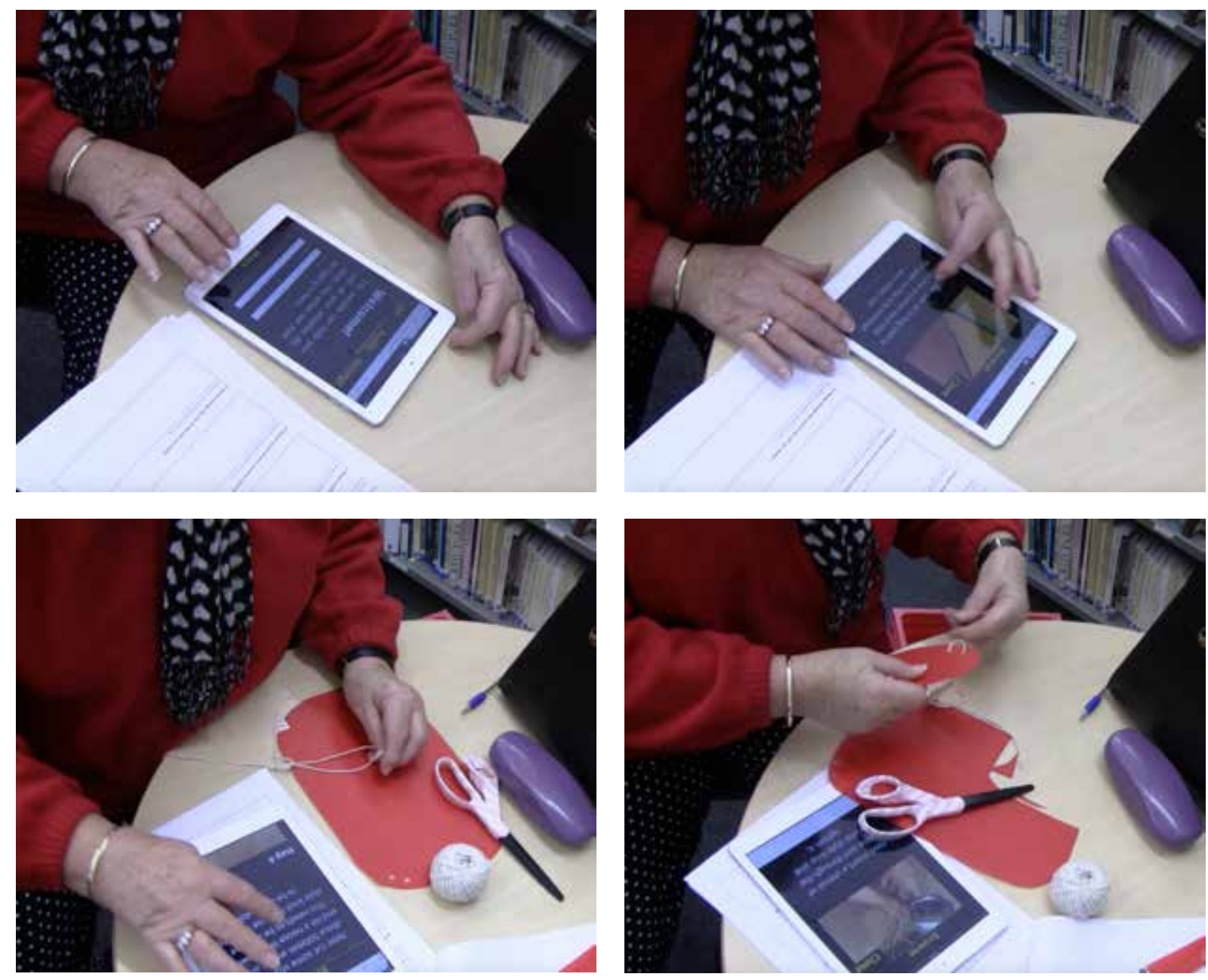

Participant B had very little experience with using the internet and handheld devices as she owned an iPad but did have an understanding of the basic concepts of navigating a website. Despite the higher level of expertise than participant A, participant B was computer illiterate by her own confession. This means she did not understand much of the jargon surrounding internet use and so stumbled at the first instruction to make an account and she did not recover as she did not complete any of the tasks. She did scroll down on the home page and came accross the create account button and seemed to hesitate when she saw it but did not click it. This could be because she did not recognise it as a button which is a problem that can occur with older adults using the internet as pointed out by Chadwick-Dias, McNulty \& Tullis (2004). Despite following the consistency heuristic and making every button uniform this problem still occured which needs to be corrected for future iterations. She did understand the concept of clicking the button however 
as she regularly went back and forth between the home page and the page displaying the full list of diy creations. Participant B stated in the task sheet two answers across each of the available text boxes: I don't know how to and I don't understand iPad.

For the second part of the user test participant B selected the utensil holder tool to make. She was given assistance in locating the three available diy creations to choose from as she was unable to complete the tasks. She initially begun by scrolling back and forth through the instructions reading through until she eventually stopped at the material list and selected a sheet of plastic and a ball of string from the materials provided. She then scrolled to the first step and and then straight to the second step. She then retrieved scissors from the materials and cut the plastic sheet to larger than the instructed size. She then retrieved a hole punch from the material selection and made holes at the top left and bottom right corners of the plastic sheet. Next she moved on to the tying of the noose which she seemed to struggle with. She then attempted to thread the string as instructed however could not because the plastic sheet had been cut too large. After realising she had cut the plastic too large she decided to stop as she did not wish to start again. In the task sheet she wrote: understood what to do got the loop wrong.

\section{Observations}

Participant B had a greater level of both experience and expertise when using the internet than participant A however still struggled greatly with using the web application. She was able to overcome many of the problems participant A faced which indicated that some of the issues he faced were related to his lack of experience. For instance the button that expands the diy creations was identifiable by participant $B$ as a button. This seemed to be because of the language used however so the visual styling in regards to the consistency heuristic is still an issue. The text prompts indicating what to do seemed to be more successful with participant $B$ also as when the diy creation she selected had it's text prompt change from select to scroll down she did.

In regards to the second portion of the user test one thing that was quite apparent was that she was referring to the images as instruction and wasn't reading many of the instructions provided. This was apparent because she 
would scroll over each instruction paragraph to the next picture. This was different from participant $A$ who seemed to use the instructions more than the picture despite his short attempt. This indicates that may be a personal thing rather than an issue with the web application however more testing would be required to find out.

\section{Questionnaire results}

Figures 46: Questionnaire answers given by participant B

\begin{tabular}{|c|c|c|c|c|c|}
\hline & $\begin{array}{l}\text { Strongly dis- } \\
\text { agree }\end{array}$ & & & & $\begin{array}{l}\text { Strongly } \\
\text { Agree }\end{array}$ \\
\hline & 1 & 2 & 3 & 4 & 5 \\
\hline $\begin{array}{l}\text { I think that } \\
\text { I would like } \\
\text { to use this } \\
\text { system } \\
\text { frequently }\end{array}$ & & & & & \\
\hline $\begin{array}{l}\text { I found the } \\
\text { system un- } \\
\text { necessarily } \\
\text { complex. }\end{array}$ & & & & & \\
\hline $\begin{array}{l}\text { I thought } \\
\text { the system } \\
\text { was easy to } \\
\text { use. }\end{array}$ & & & & & \\
\hline $\begin{array}{l}\text { I think that I } \\
\text { would need } \\
\text { the support } \\
\text { of a techni- } \\
\text { cal person } \\
\text { to be able } \\
\text { to use this } \\
\text { system. }\end{array}$ & & & & & \\
\hline $\begin{array}{l}\text { I found the } \\
\text { various } \\
\text { functions in } \\
\text { this system } \\
\text { were well } \\
\text { integrated. }\end{array}$ & & & & & \\
\hline
\end{tabular}




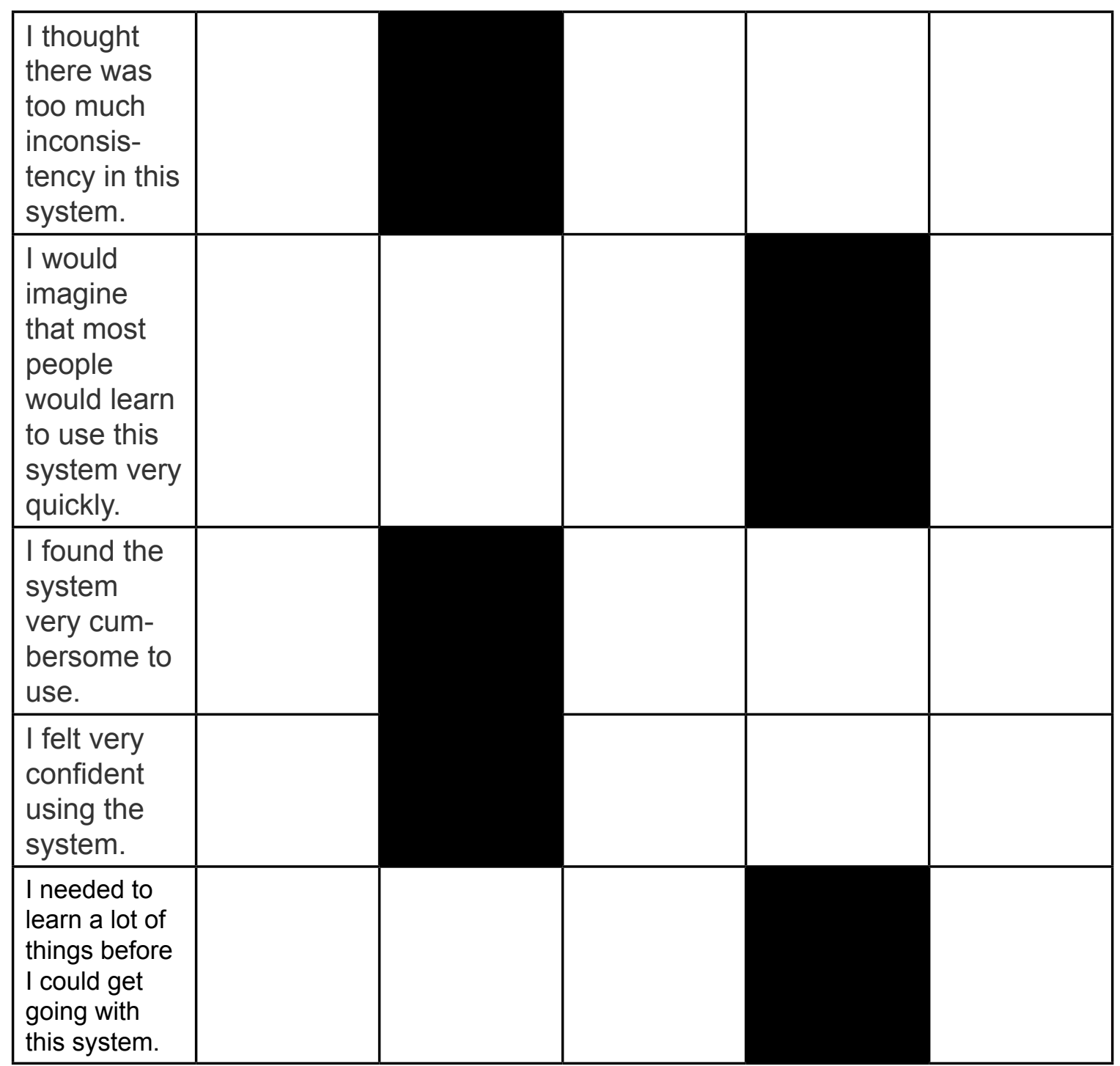

The SUS score for participant A was 55. This is a reasonable score for for the SUS. This would indicate that having some experience with using the internet makes this web application easier to use.

For the questions at the end of the questionnaire participant $A$ gave the answers:

- Question 1: Okay.

- Question 2: No.

- Question 3: helpful.

Once again these answers were short but they did more accurately reflect her experience. She did struggle more than her answers indicate though. 
Conclusion 


\section{Limitations}

Due to unforeseen and uncontrollable delays in the ethics approval process user testing was not as in depth as was required. Initially a participatory design approach was adopted however these delays resulted in this not being possible. To get more accurate and complete results in regards to psychosocial response to assistive technology a participatory design approach is required.

Participant numbers were also low due to these delays so user testing results were not fully reflective of both people with stroke induced physical disabilities and older adult demographics.

Lastly the results of this study are largely subjective due to qualitative methods being employed to gather data.

\section{Summary}

Stroke is one of the leading causes of disability formation in people internationally (Brauer et al, 2014). Stroke primarily affects older adults (Ministry of Health, 2008) establishing the two key demographics as people affected by stroke induced physical disabilities and older adults. One key issue identified for people affected by stroke induced physical disabilities was inclusion of disability within their concept of self and how that can cause rejection and/ or abandonment of assistive technology (Hocking, 1999). This is an issue because assistive technology has been shown improve independence through requiring less personal care (Agree, Freedman, 2004)(Hoening, Taylor, Sloan, 2003)(Verbrugge, Rennert, Madans, 1997). Diy is a potential way to counter this through allowing the user to customise assistive technology to meet their own needs and to alleviate stigma through aesthetic customisation. Secondly, creating diy can allow for both direct and indirect social engagement via interaction with online creator communities.

To successfully design the web application a set of heuristics was developed. These were informed by elaborating on identified demographics, a precedent analysis and technical requirements. Older adults and people affected by stroke induced physical disabilities had several factors that were considered when developing the heuristics: expertise levels, cognitive difficulties, 
perceptual difficulties, motor deficiencies and user behaviour. The combined knowledge gained from these factors indicated that the user interface would need to be clear, simple and flexible.

A precedent analysis was performed on five websites with similar functions to the web application being developed through this thesis. Initially literature examining online documentation of diy was explored to identify criteria for this analysis. From this it was identified that the documentation process needed to be seamless to allow for more accurate documentation, a process orientated approach needed to be used to to accurately reflect the process a user goes through when creating diy, and person to person expertise exchange needed to implemented. A technical analysis resulted in mobile devices being identified as the targeted device to design for and accessibility requirements to implement.

A web application was developed using the knowledge gained from developing the heuristics. This web application was tested with appropriate users and findings indicated the user interface needed to be simplified further. These results were subjective however and didn't fully represent the experiences the wider user base may have due to the participants limited experience with the internet. Further testing should be done with more experienced users to gain a more accurate insight into these practices and the psychosocial impact of diy assistive technology.

Research has been done on diy assistive technology and psychosocial impact of assistive technology however research combining these two topics is sparse and more research assessing these two topics in combination needs to be done to produce stronger results. This research however can focus on multiple platforms and not just the internet. For instance $3 \mathrm{~d}$ printing is a potential platform to look at, specifically the process of developing $3 \mathrm{~d}$ models to be printed so that general users can develop more robust assistive devices without the aid of professionals.

\section{Discussion}

This thesis sought to answer the question how can digitally connected communities have a positive influence on the psychosocial impact of stroke? This was achieved to some degree through the dissemination of diy assistive technology through a web application. Assistive technology has been shown 
to improve independence amongst people with stroke induced physical disabilities however adoption rates are low and rejection rates are high. Reasons for this have been theorised as unmet needs, difficulty in procurement etc however one theorised reason established by this thesis is the inclusion of disability into a person's concept of self.

Through the process of interviews and user testing it was confirmed that the findings of improved independence were true as the participants in this study both had assistive technology they found essential. The initial theories (unmet needs, difficulty in procurement etc) for adoption/rejection were confirmed also by participants. The primary theories this thesis established was that lack of acceptance of disability into concept of self was causing this rejection and that online dissemination of diy was a valid solution to encourage use of assistive technology. Both participants revealed through interviews that they both used assistive technology only when absolutely necessary due to wanting to be as independant as possible. Participant $A$ even stated he sometimes rejected the advice of his personal care to maintain this independence. The results of these interviews are qualitative by nature so can only be interpreted subjectively. They seem to indicate some truth to the concept of self theory though as both participants tended to act in a way that showed some rejection of their disability. Further testing needs to be done however to confirm this.

The second theory, that online dissemination of diy is a valid method to encourage use of assistive technology, could not accurately be determined through user testing as neither participant had engaged in diy in the past and neither was able to successfully complete a diy creation during the testing period. These results were somewhat unexpected as the expertise level for internet use was expected to be higher amongst participants and so some data was expected. It could be argued that the difficulty faced in not only navigating the web application but creating the diy object by both participants showed that online dissemination of diy is not an effective method for encouraging assistive technology adoption. Through the development of three diy creations, however, diy was shown to be a valid method of procuring assistive technology and filling unmet needs which indicates more testing needs to be done.

Online dissemination of diy can potentially be a means to promote adoption of assistive technology however a different user base should be considered 
for future works. This user base should have a greater expertise in regards to internet use to provide results with a stronger focus on diy. As for people with stroke induced physical disabilities diy can be effective although more testing needs to be done to prove this. Assistive technology was proven to promote independence amongst users and so any means to provoke adoption can have positive influence on a person's concept of self. 
Reference List 
Agree, E. M. and Freedman, V. A. (2004). Alleviating disability and unmet need: differential dimensions addressed by assistive technology and personal care. [working paper] Hopkins Population Center. Hopkins Population Center

Aström, M., Asplund, K., \& Aström, T. (1992). Psychosocial function and life satisfaction after stroke. Stroke, 23(4), 527-531. http://doi. org/10.1161/01.STR.23.4.527

Barber, J. (1996). The Design of Disability Products: a Psychological Perspective. British Journal of Occupational Therapy, 59(12), 561-564

Barros, A. C. de, Cruz, J, Duarte, C. (2010). 'I Made it Myself' - DIY in the Design of Assistive Devices for Stroke Patients. Proceedings of the 7th international conference on design and emotion (pp. 4-7).

Barros, A. C. de, Leitão, R., \& Ribeiro, J. (2014). Design and Evaluation of a Mobile User Interface for Older Adults: Navigation, Interaction and Visual Design Recommendations. Procedia Computer Science,27, 369-378. http://doi.org/10.1016/j.procs.2014.02.041

Becker, S. A. (2004). A study of web usability for older adults seeking online health resources. ACM Transactions on Computer-Human Interaction (TOCHI), 11(4), 387-406.

Bly, S., McDonald, D. W., Schilit, B. N., \& Torrey, C. (2007). How-To pages: Informal systems of expertise sharing. In ECSCW 2007 (pp. 391-410). Springer London.

Brandes, U. (2008). Non Intentional Design. In Design Dictionary (pp. 270272). Birkhäuser Basel.

Brauer, S. G., Eng, X. W., Hayward, K. S., Kuys, S. S., \& Lord, M. (2014). Factors Affecting the Ability of the Stroke Survivor to Drive Their Own Recovery outside of Therapy during Inpatient Stroke Rehabilitation. Stroke Research and Treatment, 2014, e626538, pp 8. http://doi. org/10.1155/2014/626538 
Chadwick-Dias, A., McNulty, M., \& Tullis, T. (2003). Web Usability and Age: How Design Changes Can Improve Performance. InProceedings of the 2003 Conference on Universal Usability (pp. 30-37). New York, NY, USA: ACM. http://doi.org/10.1145/957205.957212

Cohen, S., \& Wills, T. A. (1985). Stress, social support, and the buffering hypothesis. Psychological Bulletin, 98(2), 310-357. http://doi. org/10.1037/0033-2909.98.2.310

Day, H., Jutai, J. (1996). Measuring the Psychosocial Impact of Assistive Devices: the PIADS. Canadian Journal of Rehabilitation. 9(Number 2), 159-168. Retrieved from https://enablemob.wustl.edu/OT572D-01/RequiredArticles/PIADS\%20article.pdf

Duncan, P. W. (1994). Stroke Disability. Physical Therapy, 74(5), 399-407. Retrieved from http://ptjournal.apta.org/content/74/5/399

Dunn, D. S. (2000). Social psychological issues in disability. In R. G. Frank (Ed.), Handbook of rehabilitation psychology (pp. 565-584). Retrieved from http://search.proquest.com.helicon.vuw.ac.nz/ docview/614156570/abstract/ 1D2F6015AE614252PQ/1?accountid $=14782$

Fabend, R. (2009) Handihelp, www.handihelp.net. (Accessed 20 October 2015).

Fidler, G. (1999). The language of objects. In G. S. Fidler \& B. P. Velde (Eds.), Activities: Reality and symbol (pp. 37-46). Thorofare, NJ: Slack.

Frayling, C. (1993) Research in Art and Design. Royal College of Art Research Papers 1, 1, 1-5.

Gitlin, L. and Schemm, R. (1996). Assistive device use among older adults. University of Pittsburgh.Team Rehab report: Publishing, I.

Hanington, B. M, Martin, B (2012). Universal methods of design: 100 ways to research complex problems, develop innovative ideas, and design effective solutions. Beverly, MA: Rockport Publishers. 
Hanson, V. L. (2009, April). Age and web access: the next generation. InProceedings of the 2009 International Cross-Disciplinary Conference on Web Accessibililty (W4A) (pp. 7-15). ACM.

Hocking, C (1999). Function or feelings: factors in abandonment of assistive devices. Technology \& Disability, 11(1/2), 3.

Hocking, C. (2008). Objects of meaning: assistive devices as symbols of professionalism, identity and disability, Proceedings of ARATA 2008 National Conference, Australian Rehabilitation \& Assistive Technology Association.

Hoening, H., Taylor Jr, D. H. and Sloan, F. A. (2003). Does assistive technology substitute for personal assistance among the disabled elderly? American Journal of Public Health,93 (2), 330-337.[7] Agree, E. M. (1999). The influence of personal care and assistive devices on the measurement of disability.Social Science \& Medicine,48 427-443

Hook, J., Verbaan, S., Durrant, A., Olivier, P., \& Wright, P. (2014, June). A study of the challenges related to DIY assistive technology in the context of children with disabilities. In Proceedings of the 2014 conference on Designing interactive systems (pp. 597-606). ACM.

Hurst, A., \& Tobias, J. (2011). Empowering individuals with do-ityourself assistive technology (p. 11). ACM Press. http://doi. org/10.1145/2049536.2049541

Jeary, S., Jeary, T. (1999) Workshop Solutions, http://www.workshopsolutions.com/. (Accessed 20 October 2015).

Kuznetsov, S., \& Paulos, E. (2010). Rise of the Expert Amateur: DIY Projects, Communities, and Cultures. In Proceedings of the 6th Nordic Conference on Human-Computer Interaction: Extending Boundaries (pp. 295-304). New York, NY, USA: ACM. http://doi. org/10.1145/1868914.1868950

Link, B., \& Phelan, J. (2001). Conceptualizing Stigma. Annual Review of Sociology, 27, 363-385. Retrieved from http://www.jstor.org.helicon.vuw. ac.nz/stable/2678626 
McCracken, G. (1988). Culture and consumption: New approaches to the symbolic character of consumer goods and activities. Bloomington, IN: Indiana University Press.

Ministry of Health (2008). A Portrait of Health: Key results of the 2006/07 New Zealand Health Survey. Retrieved April 20, 2016, from http:// www.health.govt.nz/publication/portrait-health-key-results-2006-07new-zealand-health-survey

Mogey, N. (1999). Likert scale information page. LEARNING TECHNOLOGY DISSEMINATION INITIATIVE. Retrieved July 28 2016, from http://www. icbl.hw.ac.uk/Itdi/cookbook/info_likert_scale/index.html\#endhead

New Zealand Government (2016). Web accessibility for designers Retrieved December 3rd, 2015, from https://webtoolkit.govt.nz/guidance/ design-and-development/quick-reference-guides/web-accessibility-for-designers/

Nielsen, J. (1994b). Heuristic evaluation. In Nielsen, J., and Mack, R.L. (Eds.), Usability Inspection Methods, John Wiley \& Sons, New York, NY.

Pape, T. L.-B., Kim, J., \& Weiner, B. (2002). The shaping of individual meanings assigned to assistive technology: a review of personal factors. Disability and Rehabilitation, 24(1-3), 5-20. http://doi. org/10.1080/09638280110066235

Pew Research Center (2014). World Wide Web Timeline. Retrieved April 27, 2016, http://www.pewinternet.org/2014/03/11/world-wide-web-timeline/

Research New Zealand (2015). A Report on a Survey of New Zealanders' Use of Smartphones and other Mobile Communication Devices 2015. http:// www.researchnz.com/pdf/Special\%2OReports/Research\%20New\%20 Zealand\%20Special\%20Report\%20-\%20Use\%20of\%20Smartphones. pdf (accessed 5 March 2016).

Sciarra, P., Silbermann, B., and Sharp, E. (2006) Pinterest, https://www.pinterest.com/. (Accessed 13 October 2015). 
Stroke.org (2016). National Stroke Association, http://www.stroke.org (accessed 19 April 2016).

Taylor, S. E. (1983). Adjustment to threatening events: A theory of cognitive adaptation. American Psychologist, 38(11), 1161-1173. http://doi. org/10.1037/0003-066X.38.11.1161

Tseng, T., \& Resnick, M. (2014, June). Product versus process: representing and appropriating DIY projects online. In Proceedings of the 2014 conference on Designing interactive systems (pp. 425-428). ACM.

Teoh, V., Sims, J., \& Milgrom, J. (2009). Psychosocial predictors of quality of life in a sample of community-dwelling stroke survivors: a longitudinal study. Topics in Stroke Rehabilitation, 16(2), 157-166. http://doi. org/10.1310/tsr1602-157

Williamson, G. M., \& Shaffer, D. R. (2002). The Activity Restriction Model of Depressed Affect. In G. M. Williamson, D. R. Shaffer, \& P. A. Parmelee (Eds.),Physical Illness and Depression in Older Adults (pp. 173-200). Springer US. Retrieved fromhttp://link.springer.com/chapter/10.1007/0-306-47178-7_9

Lagerkrans, E., Riedel, D. (2006) Spinalistips, http://www.spinalistips.se/. (Accessed 2 February 2016).

Landreville, P., Desrosiers, J., Vincent, C., Verreault, R., \& Boudreault, V. (2009). The role of activity restriction in poststroke depressive symptoms. Rehabilitation Psychology, 54(3), 315-322. http://doi.org/http:// dx.doi.org.helicon.vuw.ac.nz/10.1037/a0016572

Vagias, Wade M. (2006). Likert-type scale response anchors. Clemson International Institute for Tourism \& Research Development, Department of Parks, Recreation and Tourism Management. Clemson University.

Verbrugge, L. M., Rennert, C. and Madans, J. H. (1997). The Great Efficacy of Personal and Equipment Assistance in Reducing Disability. American Journal of Public Health,87 (3), 384-392. 
Vincent, C., Deaudelin, I., Robichaud, L., Rousseau, J., Viscogliosi, C., Talbot, L. R., ... (2007). Rehabilitation needs for older adults with stroke living at home: perceptions of four populations. BMC Geriatrics, 7(1), 20. http://doi.org/10.1186/1471-2318-7-20

Wilheim, E., J. (2005) Instructables, http://www.instructables.com/. (Accessed 13 October 2015).

\section{List of figures}

Figures 1 - 3. Wilheim, E., J. (2005) Instructables [Screen Captures]. (2016). Retrieved from http://www.instructables.com/.

Figures 4 - 5. Sciarra, P., Silbermann, B., and Sharp, E. (2006) Pinterest [Screen Captures]. (2016). Retrieved from https://www.pinter est.com/.

Figures 6 - 7. Fabend, R. (2009) Handihelp [Screen Captures]. (2016). Re trieved from www.handihelp.net.

Figures 8 - 9. Jeary, S., Jeary, T. (1999) Workshop Solutions [Screen Cap tures]. (2016). Retrieved from http://www.workshopsolutions.com/.

Figures 10 - 11. Lagerkrans, E., Riedel, D. (2006) Spinalistips [Screen Cap tures]. (2016). Retrieved from http://www.spinalistips.se/. 


\section{Appendix}

Health
and
Disability
Ethics
Committees

Health and Disability ethics Com mitte

Mnis ty of Hes:

Freberg Build

20 Aitken Ste

DOBox 501

Welingt

601

08004 ETHIC hdecolmohgon

10 February 2016

Dr Brian Robinson

Graduate School of Nursing. Midwifery \& Health

PO Box 7625

Nemown 6242

Dear Dr Robinson

$\begin{array}{lll}\operatorname{Re}: \text { Ethics ref: } & 16 / C E N / 5 \\ \text { Study itle: } & \text { Developing interactive Devices and Games for Physical Therapies } \\ & \text { in Stroke Recovory }\end{array}$

This application was reviewed by the Central Heath and Disability Ethics Commiltee and provisionally aporoved pending receipt of further information. This decision was made through the HDEC-Full Review pathway.

\section{summay of study}

This study is a joint collaboraf on between the Victoria University of Wellington School of Deed gn and the Victoria Universily Graduate School of Nursing. Midwifery and Health and senior physiotherapists at AUT University in Auckland. It is a 'usa bility' study which will aim to test two things: sofware and computer controllers in stroke patients as potentially useful rehabilitaton aids.

The tesearch team is seeking ethical approval for 4-5 design projects every 3 year for 3 years so for 12.15 projects and around 100 partidpants. There is not one pertcular piece of software but students will build on previous students' workso the software and physical controllers may vary over the three years.

The researchers intend to test in the participant's home. A design student will explain the device and watch the partidpant use the device and record the partidpant using the device with a sensor and photographvideos and secondy interview the participant and record data.

\section{Summary of eftical issues (resolved)}

The main ethical issues considered by the Committee and were addressed by the Rese archer are as follows.

0. The commitee asked what 3-4 projects are lined up for this year. Dr Robinson explained that one project involved students developing games guiding an astronaut around a scieen that would inform other projects. The overall aim is to cre ate a blanket applicafion to cover these students. Dr Robinson expl ained that the same game will always be used but a different style of mouse will be tested The games vill be made progressively more dificult to help enhance movement This game "level $r$ " will be tested to see whether stroke patients can us the device. The idea is to use upper limb movement to stimulate neural plasticity and studen s will or eate a portillo of games with these devices. 
